\title{
Effects of maternal taurine supplementation on maternal dietary intake, plasma metabolites and fetal growth and development in cafeteria diet fed rats
}

\author{
Arzu Kabasakal Cetin ${ }^{1}$, Tugba Alkan Tug ${ }^{1}$, Atila Gulec $^{1}$, Asli Akyol ${ }^{\text {Corresp. } 1}$ \\ 1 Department of Nutrition and Dietetics, Faculty of Health Sciences, Hacettepe University, Ankara, Türkiye \\ Corresponding Author: Asli Akyol \\ Email address: asli.akyol@hacettepe.edu.tr
}

Background: Maternal obesity may disrupt the developmental process of the fetus during gestation in rats. Recent evidence suggests that taurine can exert protective role against detrimental influence of obesogenic diets. This study aimed to examine the effect of maternal cafeteria diet and/or taurine supplementation on maternal dietary intake, plasma metabolites, fetal growth and development. Methods: Female Wistar rats were fed a control (CON) diet, CON supplemented with 1.5\% taurine in drinking water (CONT), cafeteria diet (CAF) or CAF supplemented with taurine (CAFT) from weaning. After 8 weeks all animals were mated and maintained on the same diets during pregnancy and lactation. Results: Dietary intakes were significantly different between the groups. Both CAF and CAFT fed dams consumed less water in comparison to CON and CONT dams. Taurine supplementation only increased plasma taurine concentrations in CONT group. Maternal plasma adiponectin concentrations increased in CAF and CAFT fed dams compared to CON and CONT fed dams and there was no effect of taurine. Hyperleptinemia was observed in CAF fed dams but not in CAFT fed dams. Malondialdehyde was significantly increased only in CAF fed dams. Litter size, sex ratio and birth weight were similar between the groups. There was an increase in neonatal mortality in CONT group. Discussion: This study showed that maternal taurine supplementation exerted modest protective effects on cafeteria diet induced maternal obesity. The increased neonatal mortality CONT neonates indicates possible detrimental effects of taurine in the setting of normal pregnancy. Therefore, future studies should investigate the optimal dose of taurine supplementation and long term potential effects on the offspring. 
1 Effects of Maternal Taurine Supplementation on

2 Maternal Dietary Intake, Plasma Metabolites and Fetal

3 Growth and Development in Cafeteria Diet Fed Rats 4

Arzu Kabasakal Cetin ${ }^{1}$, Tugba Alkan Tug ${ }^{1}$, Atila Gulec ${ }^{1}$, Asli Akyol ${ }^{1}$

6

7

${ }^{1}$ Department of Nutrition and Dietetics, Faculty of Health Sciences, Hacettepe University,

806100 Sihhiye, Ankara, Turkey

9

10 Corresponding Author:

11 Asli Akyol

12 Email address: asli.akyol@hacettepe.edu.tr 


\section{Abstract}

37 Background: Maternal obesity may disrupt the developmental process of the fetus during gestation in rats. Recent evidence suggests that taurine can exert protective role against detrimental influence of obesogenic diets. This study aimed to examine the effect of maternal cafeteria diet and/or taurine supplementation on maternal metabolic health and offspring growth 41 at weaning.

42 Methods: Female Wistar rats were fed a control (CON) diet, CON supplemented with $1.5 \%$ 43 taurine in drinking water (CONT), cafeteria diet (CAF) or CAF supplemented with taurine 44 (CAFT) from weaning. After 8 weeks all animals were mated and maintained on the same diets 45 during pregnancy and lactation.

46 Results: Dietary intakes were significantly different between the groups. Both CAF and CAFT fed dams consumed less water in comparison to CON and CONT dams. Maternal plasma taurine concentrations decreased in CAF fed dams and normalised by taurine supplementation in CAFT group. Maternal plasma adiponectin concentrations increased in CAF and CAFT fed dams compared to CON and CONT fed dams and there was no effect of taurine. Hyperleptinemia was observed in CAF fed dams but not in CAFT fed dams. Malondialdehyde was significantly increased only in CAF fed dams. Litter size, sex ratio and birth weight were similar between the groups. There was an increase in neonatal mortality in CONT group.

Discussion: This study showed that maternal taurine supplementation exerted modest protective effects on cafeteria diet induced maternal obesity. The increased neonatal mortality CONT neonates indicates possible detrimental effects of taurine in the setting of normal pregnancy. Therefore, future studies should investigate the optimal dose of taurine supplementation and long term potential effects on the offspring.

Keywords: Taurine, cafeteria diet, pregnancy, obesity, rats

60

61

62

63 


\section{Introduction}

77 Obesity has become a significant public health problem due to its increasing prevalence at an

78

79

80

81

82

83

84

85

86

87

88

89

90

91

92

93

94

95

96

97

98

99

100

101

102

103

104

105

106

107

108

109

110

111

112

113

114

115 alarming rate ( $\mathrm{Ng}$ et al., 2013). Lifestyle changes, including increased energy intake and decreased physical activity are considered as the main contributors of this outcome (Popkin, 2015). The rate of obesity and overweight in women of child-bearing age is also increasing (Fisher et al., 2013). Previous studies suggested that children born to mothers with maternal obesity are at higher risk for unfavorable birth outcomes and health problems (Nagl et al., 2017; Ayonrinde et al., 2017). The identification of obesity related complications during pregnancy and developing effective interventions as early as possible to prevent the development of childhood obesity is vital (Blake-Lamb et al., 2016). For this purpose, animal models of obesity are crucial to examine the mechanisms involved in the progression of obesity.

Through the developmental origins of health and disease paradigm, accumulating evidence suggest that maternal obesity or overnutrition during pregnancy results in the development of components of metabolic syndrome in the offspring (Desai et al., 2014; Raipuria et al., 2015; Dias-Rocha et al., 2018). In particular, offspring born to dams fed a hyper-energetic cafeteria diet during gestation and/or lactation exhibited increased body weight (Benkalfat et al., 2011), reduced muscle force (Bayol et al., 2009), altered hepatic gene expression in insulin signaling pathway (Daniel et al., 2014) and different behavioral parameters (Speight et al., 2017). Studies reported that these effects could be reversed by specific interventions such as increasing maternal physical activity (Son et al., 2019) or including bioactive food components to obesogenic diets (Sheen et al., 2018).

Taurine, 2-aminoethane sulfonic acid, is involved in various metabolic pathways both in human and rodents (Nielsen et al., 2017). It serves crucial functions in biological processes that are related with detoxification, membrane integrity, bile acid conjugation, calcium levels and regulation of osmosis (Ince at al., 2017). Recently, few studies reported that taurine may exert a protective influence on oxidative stress induced by different disruptors in rodent (Rashid, Das \&Sil, 2013; Zheng et al., 2017). More specifically, one study reported that offspring exposed to a maternal obesogenic diet with taurine supplementation during pregnancy and lactation had partially recovered pro-inflammatory hepatic profile (Li et al., 2013). Similar rescuing effect of taurine was also observed in maternal fructose-induced obesity (Li et al., 2015) and low protein diet models (Larsen et al., 2017).

The cafeteria diet is a robust model of inducing dietary obesity in laboratory animals, promoting exacerbated hyperphagia and inflammation in a pronounced level (Sampey et al., 2011; Oliva et al., 2019). To date few studies have investigated the possible protective role of taurine within obesogenic diet models on pregnancy outcomes in rats. Therefore, the aim of this study was to examine whether taurine given with cafeteria diet prior to gestation, during gestation and lactation exerts any protective effects on dietary intakes, plasma circulating metabolites, amino acid profile and fetal growth and development until weaning. 


\section{Materials \& Methods}

\section{Animals and diets}

118 The experiments were performed under the license from the Ethics Committee of Hacettepe

119 University, Ankara, Turkey, number: 2015/01. Animals were obtained from Laboratory Animals

120 Research and Application Centre. All animals were housed individually in plastic cages and

121 subjected to a $12 \mathrm{~h}$ light-dark cycle at a temperature of $20-22{ }^{\circ} \mathrm{C}$ and $45 \%$ humidity. The animals

122 were housed on wood shavings and had ad libitum access to food and water at all times. Animal

123 care, feeding and maintaining of housing conditions were performed and checked by researchers

124 and animal house personnel. After one week of habituation period, Virgin female Wistar rats

125 (aged 4 weeks) were randomly allocated to be fed either a control chow diet (CON; n=6), control

126 chow diet supplemented with 1.5\% taurine in drinking water (Li et al., 2013; Li et al., 2015)

127 (CONT; $n=7)$, cafeteria diet $(\mathrm{CAF} ; \mathrm{n}=7)$ or cafeteria diet supplemented with $1.5 \%$ taurine in

128 drinking water (CAFT; $\mathrm{n}=7$ ) for 8 weeks. In total, 27 female Wistar rats were used.

129 Experimenters were not blind to treatment. Animals were then paired with a Wistar stud male

130 and mating was confirmed by the appearance of a semen plug. The male rat was removed as

131 soon as detecting semen plug. Animals continued to consume the same diets during pregnancy

132 and lactation. Cafeteria diet consisted of control chow diet ( $\% 6$ fat, $\% 71$ carbohydrate, $\% 23$

133 protein, energy $2800 \mathrm{kkal} / \mathrm{kg}$, Kalecik, Kırıkkale, Turkey) with a random selection of highly

134 energetic and palatable human foods. Data related to cafeteria diet were collected as previously

135 described in Buyukdere et al., 2019 and Akyol et al., 2009. Briefly, the highly energetic and

136 palatable human foods include biscuits, potato and corn crisps, milk chocolate, metro chocolate

137 bar, kashar cheese, jelly candy, chocolate cake and peanuts. Four of these foods were given in a

138 cup on the cage floor daily in excess quantities. In order to maintain variety two of these foods

139 were replaced with new ones daily. Hence, rats did not have the same foods for more than two

140 consecutive days at a time. All components of the cafeteria diet, including chow and water were

141 individually weighed in and out of the cage between 09.00 and 10.00 hours daily. Daily intakes

142 of energy and macronutrients were calculated from the manufacturers' data, after allowing for

143 weight changes due to drying of foods, as described previously (Akyol, Langley-Evans \&

144 McMullen, 2009). The animals were weighed daily during pre-mating, mating, birth and

145 gestation periods. Weight loss of more than $15 \%$ of body weight, reduction in abilities of

146 consuming diets and water or inability to walk properly were established as criteria for excluding

147 animals prior to the planned end of the experiment but all of the animals successfully completed

148 the study period. Thus, all analyses were performed through CON; n=6, CONT; n=7, CAF; n=7

149 and CAFT; $\mathrm{n}=7$.

150 At birth, the birth weight, sex ratio and litter size were recorded. Litters were then culled 151 to a maximum of eight pups (four males and four females, where possible). Body weights of all

152 animals were recorded daily. Neonatal mortality was evaluated relative to born litter size at birth 153 and calculated by dividing number of dead pups to litter size (Li et al., 2013; Li et al., 2015). At 154 the end of lactation, mothers and three male and three female offspring from each litter were 155 culled using $\mathrm{CO}_{2}$ asphyxia after overnight fasting. $\mathrm{CO}_{2}$ asphyxia was applied by $\mathrm{CO}_{2}$ euthanasia 
156

157

158

159

160

161

162

163

164

165

166

167

168

169

170

171

172

173

174

175

176

177

178

179

180

181

182

183

184

185

186

187

188

189

190

191

192

193

194

195

apparatus found in rat's home cages. Surviving animals were not allowed to see the procedure. Animals were exposed to $5.6 \mathrm{~L} / \mathrm{min} \mathrm{CO}_{2}$ until complete cessation of breathing is observed for a minimum of 5 minutes. Cervical dislocation was performed to assure euthanasia. Body cavities of animals were opened and blood samples were taken by cardiac puncture and, major organs (liver, kidneys, heart, gonadal and peri-renal adipose tissues) were dissected separately and weighed. The remaining offspring used in a different study. Figure 1 shows the study design. The study protocol was registered at The Scientific And Technological Research Council of Turkey, number 115 S538.

\section{Plasma Analyses}

All blood samples were collected into heparinized capillary tubes and stored on ice until centrifuged in a hematocrit centrifuge. Plasma was collected and stored at $-80{ }^{\circ} \mathrm{C}$ until required for analysis. Maternal plasma metabolite analyses were performed on fasting samples collected at weaning. Plasma leptin, adiponectin and insulin-like growth factor I (IGF-I) (R\&D Systems, Inc., Minneapolis, MN 55413, USA), insulin (Raybiotech, 3607 Parkway Lane, Suite 100 Norcross, GA 30092), total cholesterol and triglyceride (Hangzhou Eastbiopharm Co.,Ltd., Blue Ocean International Times Mansion, No.39 Yile road), c-peptide and HbA1C (Elabscience, Catalog No: E-EL-R0032) were measured by rat specific enzyme-linked immunosorbent assay. Plasma glucose and malondialdehyde were measured using commercially sourced assay kits (Cayman Chemical, 1180 E. Ellsworth Rd. Ann Arbor, MI. USA). Plasma taurine concentrations were analyzed using a Shimadzu LC-30 UHPLC system with auto sampler. Plasma amino acid analyses were performed using a GC amino acid kit (EZ:faast; Phenomenex, Torrance, CA, USA) (Badawy, Morgan \& Turner, 2008). All assays were performed according to manufacturer's instructions and intra- and inter-assay coefficients of variation were $<10 \%$.

\section{Statistical Analyses}

All data were analyzed using the Statistical Package for Social Sciences (version 16; SPSS, Inc., Chicago, IL, USA). Data were tested for normality using Shapiro-Wilks normality test and visual analytical methods (histograms, probability plots). Data that did not meet the criteria required for parametric analysis were transformed to achieve normal distribution and equal variance. A general linear model analysis of variance (ANOVA) (fixed factors, maternal diet) was used for normally distributed data. Repeated-measures ANOVA was performed to compare the mean differences between groups in those parameters measured at different time points (for example, weekly body weights and energy intakes). The effect of maternal diet on fetal outcomes was assessed using a general linear model analysis of variance (ANOVA) (fixed factors, maternal diet and sex). Post hoc testing (Tukey's test) was applied for the significant main effects of the diet. Data that were not been normally distributed analysed using the non-parametric KruskalWallis test and comparisons between two groups were performed Mann-Whitney U-test. The proportion of neonatal deaths per litter was analyzed via Chi-square test. Values are expressed as mean values with their standard errors. $\mathrm{p}<0.05$ was considered statistically significant. Power 
196

197

198

199

200

201

202

203

204

205

206

207

208

209

210

211

212

213

214

215

216

217

218

219

220

221

222

223

224

225

226

227

228

229

230

231

232

233

234

235

analysis indicated that 6 animals per group was sufficient to detect a minimum $12 \%$ energy intake difference with a power of $80 \%$ and alpha 0.05 (Akyol, Langley-Evans \& McMullen, 2009). The study data is submitted as a supplementary file.

\section{Results}

During pre-gestational period energy intakes of dams did not differ between groups $(\mathrm{P}=0.062)$ (Table 1). CAF and CAFT fed animals had significantly higher intakes of fat $(\mathrm{P}<0.001)$, and $\mathrm{Na}$ $(\mathrm{P}<0.001)$, and significantly lower intakes of protein $(\mathrm{P}<0.001)$. While carbohydrate intake of CAF and CAFT fed animals was significantly lower than CONT fed animals $(\mathrm{P}<0.05)$, CAF fed animals exhibited a similar carbohydrate intake in comparison to $\mathrm{CON}$ fed animals $(\mathrm{P}=0.105)$.

There were no statistically significant differences in energy intake between the groups during gestation and lactation $(\mathrm{P}>0.05)$. CAF and CAFT had significantly higher fat $(\mathrm{P}<0.001)$ and $\mathrm{Na}$ $(\mathrm{P}<0.001)$, and significantly lower protein $(\mathrm{P}<0.001)$ and carbohydrate $(\mathrm{P}<0.001)$ intake during gestation (Table 1). Alike pre-gestational and gestational periods, fat $(\mathrm{P}<0.001)$ intake was significantly higher in CAF and CAFT whereas protein $(\mathrm{P}<0.001)$ and carbohydrate $(\mathrm{P}<0.001)$ intakes were significantly lower during the lactation period. A significant interaction between diet and study weeks also influenced fat and protein intake during gestation and lactation $(\mathrm{P}<0.05)$.

Since taurine was added to drinking water in CONT and CAFT, water intake of animals was also recorded (Figure 2(a)). During the pre-gestational period CAF (28.01 $\pm 0.82 \mathrm{~g} /$ day) and CAFT (27.81 $\pm 0.82 \mathrm{~g} /$ day) consumed significantly lower amount of water than CON $(41.31 \pm 0.88$ $\mathrm{g} /$ day $)$ and CONT $(45.77 \pm 0.82 \mathrm{~g} /$ day $)(\mathrm{P}<0.001)$. During the gestation and lactation periods a similar pattern was observed in groups as CAF (Gestation: 29.72 $\pm 1.44 \mathrm{~g} /$ day, lactation: $42.16 \pm 2.94 \mathrm{~g} / \mathrm{day}$ ) and CAFT (Gestation: 29.85 $\pm 1.44 \mathrm{~g} / \mathrm{day}$, lactation: $42.07 \pm 2.94 \mathrm{~g} / \mathrm{day}$ ) consumed significantly lower amount of water in comparison to CON (Gestation: $51.54 \pm 1.56$ $\mathrm{g} /$ day, lactation: $94.84 \pm 3.18 \mathrm{~g} /$ day) and CONT (Gestation: $55.15 \pm 1.44 \mathrm{~g} /$ day, lactation: $101.89 \pm 2.94 \mathrm{~g} /$ day $)(\mathrm{P}<0.001)$. Estimated taurine intake of CAFT dams $(2.52 \pm 0,19 \mathrm{mg} / \mathrm{g}$ body weight/day) was significantly lower than CONT dams (3.95 $\pm 0.19 \mathrm{mg} / \mathrm{g}$ body weight/day) during the pre-gestational period $(\mathrm{P}<0.001)$ (Figure 2(b)). During the gestation and lactation periods a similar pattern was observed in CAFT group (Gestation: $1.68 \pm 0.14 \mathrm{mg} / \mathrm{g}$ body weight/day, lactation: $2.86 \pm 0.28 \mathrm{mg} / \mathrm{g}$ body weight/day) as estimated taurine consumption of CAFT dams was significantly lower than CONT dams (Gestation: $3.11 \pm 0.14 \mathrm{mg} / \mathrm{g}$ body weight/day, lactation: $5.47 \pm 0.28 \mathrm{mg} / \mathrm{g}$ body weight/day $)(\mathrm{P}<0.001)$.

The body weights of the dams did not vary significantly at the beginning of the experiment. All animals gained weight during the pre-pregnancy and pregnancy periods (Figure 3). A significant interaction between diet and study weeks influenced average body weights during pre-gestational period (CON: $168.05 \pm 1.69 \mathrm{~g}$, CONT: $179.99 \pm 1.69 \mathrm{~g}, \mathrm{CAF}: 178.77 \pm 1.57 \mathrm{~g}$ and CAFT: $175.62 \pm 1.57 \mathrm{~g}$; interaction between diet*study weeks $\mathrm{P}=0.002)$. During the pregnancy period, all groups exhibited similar gestational body weights (CAF: $272.08 \pm 4.78 \mathrm{~g}$, CAFT: $268.21 \pm 4.78$ g, CON: $252.22 \pm 5.16$ g, CONT: $267.88 \pm 4.78$ g, $\mathrm{P}=0.369$ ). Weight gain 
236

237

238

239

240

241

242

243

244

245

246

247

248

249

250

251

252

253

254

255

256

257

258

259

260

261

262

263

264

265

266

267

268

269

270

271

272

273

274

275

slowed in rats fed the CAFT $(243.48 \pm 4.58 \mathrm{~g})$ diet during lactation in comparison with those fed the CONT (276.14 $\pm 4.58 \mathrm{~g})(\mathrm{P}=0.035)$. Both CAF and CAFT groups exhibited weight loss during lactation.

Dietary treatment during pre-gestational, gestational and lactation periods significantly influenced maternal liver, kidney and adipose tissue weights at the end of the lactation period (Table 2). Taurine addition to cafeteria diet or chow diet did not alter liver weight between CON and CONT or CAF and CAFT. However, CAF and CAFT had significantly lower liver weights than CON and CONT $(\mathrm{P}<0.001)$. Both of the right and left kidney weights exhibited a similar pattern as CAF and CAFT had significantly lower kidney weights than CON and CONT $(\mathrm{P}<0.05)$. Fat depot mass data indicated that taurine addition to cafeteria diet did not exert a protective effect on gonadal and peri-renal fat mass since CAF and CAFT had significantly heavier values than $\mathrm{CON}$ and $\mathrm{CONT}(\mathrm{P}<0.001)$ and there were no significant difference between CAF and CAFT groups.

Maternal plasma glucose, insulin, IGF-1, C-peptide, cholesterol and triglyceride were unaffected by dietary treatment at the end of the lactation (Table 3). CONT, CAF and CAFT displayed higher levels of $\mathrm{HbAlc}$ than CON. Leptin was significantly higher in CAF compared to CON and CONT whereas it was similar to all other three groups in CAFT. Adiponectin was significantly higher in CAF and CAFT than CON and CONT. Malondialdehyde was significantly higher only in CAF in comparison to CON and CONT. Maternal plasma taurine was increased in CONT compared to CON, CAF and CAFT (Table 4). Also, taurine was significantly lower in CAF than CON, CONT and CAFT. CAF and CAFT exhibited higher levels of serine and lower levels of tyrosine than CON. Phenylalanine was lower and aspartic acid higher in CAFT than CON.

Litter size (CON: $11.00 \pm 1.19$, CONT: $10.43 \pm 1.11$, CAF: $9.57 \pm 1.11$, CAFT: $9.57 \pm 1.11$, $\mathrm{P}=0.775)$ and sex ratio (male:female) (CON: $0.76 \pm 0.49$, CONT: $1.22 \pm 0.46$, CAF: $1.56 \pm 0.46$, CAFT: $1.79 \pm 0.46, \mathrm{P}=0.464)$ were similar between the study groups. Similarly, birth weights of pups did not differ between groups $(\mathrm{p}=0.532)$ but male offspring's birth weights were higher than female offspring (CON male: $5.87 \pm 0.13 \mathrm{~g}$, female: $5.40 \pm 0.10 \mathrm{~g}$; CONT male: $5.70 \pm 0.11 \mathrm{~g}$, female: $5.36 \pm 0.11 \mathrm{~g}$; CAF male: $5.64 \pm 0.11 \mathrm{~g}$, female: $5.30 \pm 0.12 \mathrm{~g}$ and CAFT male: $5.64 \pm 0.12 \mathrm{~g}$, female: $5.37 \pm 0.11 \mathrm{~g}, \mathrm{P}<0.001)$. Maternal taurine supplementation significantly increased the proportion of neonatal deaths per litter only in the CONT group and sex of the animals had no effect on this outcome (CONT: $12.3 \%$ versus CON: $3.0 \%$, CAF: $4.5 \%$ and CAFT: $1.5 \%$, $\mathrm{P}=0.023$ ). Those offspring died during the first week of lactation.

Offspring weight gain was significantly influenced by maternal diet $(\mathrm{P}<0.001)$ and study weeks $(\mathrm{P}<0.001)$ during lactation but there was no effect of sex (Figure 4). Maternal diet and study weeks exhibited a significant interaction $(\mathrm{P}<0.001)$. Although birth weight did not vary between the groups, this situation disappeared over time and CAF and CAFT offspring displayed lower body weights in comparison to CON and CONT offspring in both genders (CON, male: $19.00 \pm 0.60$ g, female: $18.88 \pm 0.47 \mathrm{~g}$; CONT, male: $20.31 \pm 0.55 \mathrm{~g}$, female: $20.44 \pm 0.50 \mathrm{~g}$; CAF, male: $16.91 \pm 0.50 \mathrm{~g}$, female: $16.95 \pm 0.53 \mathrm{~g}$; CAFT male: $16.34 \pm 0.48 \mathrm{~g}$, female: $16.56 \pm 0.49 \mathrm{~g}$,

Peer) reviewing PDF | (2020:12:56715:1:2:NEW 24 Mar 2021) 
$276 \mathrm{P}<0.001$ ). In addition, maternal diet significantly influenced liver, brain, kidney and heart 277 weights of offspring in terms of percentage of body weight in both genders at the end of lactation 278 (Table 5). Fetal exposure to cafeteria diet led to lower liver and kidney weights compared with $279 \mathrm{CON}$ and CONT groups $(\mathrm{P}<0.001)$. Liver and kidney weights of CAFT offspring exhibited 280 similar patterns like CAF offspring $(\mathrm{P}<0.001)$. However, CAFT offspring had significantly 281 heavier brain weight than $\mathrm{CON}(\mathrm{P}=0.004)$ and CONT offspring $(\mathrm{P}=0.001)$. Offspring that were 282 exposed to maternal cafeteria diet exhibited heavier heart weights in comparison to CON and 283 CONT groups $(\mathrm{P}<0.001)$. Furthermore, a reduction in heart weight was observed in the offspring 284 of $\mathrm{CAFT}(\mathrm{P}=0.011)$.

285

286

287

288

289

290

291

292

293

294

295

296

297

298

299

300

301

302

303

304

305

306

307

308

309

310

311

312

313

314

315

\section{Discussion}

The influence of maternal dietary strategies to prevent the development of chronic diseases on the developing offspring is relatively unknown in contrast to the more direct inferences of neonatal health. Few animal studies support the notion that taurine supplementation may trigger differences in metabolic functions and physiology (Rashid, Das \& Sil, 2013; Zheng et al., 2017). However, it is not clear whether such effects can continue on throughout pre-pregnancy, pregnancy and lactation. The maternal metabolic health during these periods is an important determinant of health status of offspring. Both animal and human studies revealed that gestation period does not terminate with birth but with end of lactation (Stuebe AM \&Rich-Edwards JW, 2009) Hence, the primary aim of this study was to compare the effect of a maternal cafeteria diet with taurine supplemented cafeteria diet in terms of pre-pregnancy nutritional status, pregnancy progression, outcomes and fetal growth and development throughout lactation. In this regard, firstly, the present study showed significant nutritional and metabolic changes in dams in response to a maternal cafeteria diet at weaning. More specifically, maternal taurine supplementation reversed some of these changes at a modest level through preventing maternal hyperleptinemia, reducing malondialdehyde and increased plasma taurine levels. Furthermore, increased neonatal mortality was observed in taurine supplemented-control group.

Previous studies reported that ingestion of the cafeteria diet before pregnancy led to hyperphagia and increased energy intake (Akyol, Langley-Evans \& McMullen, 2009; Crew, Waddell \& Mark, 2016; Sanchez-Blanco et al., 2016). Unlike this finding, energy intake of cafeteria fed dams did not differ from other groups prior to gestation in this study. One explanation might become the expression of the data as energy intake was normalized to body weight in the current study. Furthermore, it was suggested that providing more food items (for example 40 highly palatable energy-dense human food) made the cafeteria diet more successful at sustained hyperphagia and greater weight gain (George et al., 2019). Gugusheff et al. (2016) reported similar energy intakes between cafeteria and control dams throughout pre-gestation and gestation periods which may be associated with presenting less food items in cafeteria diet. Also, energy intake of cafeteria fed dams did not differ from other groups during gestation in the current study. Similarly, one study reported that energy intakes of cafeteria fed dams were similar to other groups (Ferro Cavalcante et al., 2014) whereas other studies showed higher 
316 energy intakes during gestation in cafeteria group (Akyol, Langley-Evans \& McMullen, 2009; 317 Sanchez-Blanco et al., 2016; Vithayathil et al., 2018). The present study demonstrated that 318 energy intake was not different between groups during lactation, which has been reported

319

320

321

322

323

324

325

326

327

328

329

330

331

332

333

334

335

336

337

338

339

340

341

342

343

344

345

346

347

348

349

350

351

352

353

354

355 previously (Ferro Cavalcante et al., 2014), but not in all studies (Bayol, Farrington \& Stickland, 2007; Speight et al., 2017; Vithayathil et al., 2018). These contradictory results may be due to type of foods used in the cafeteria diet, differences in the duration and timing of intervention. Cafeteria diet is an unbalanced diet with a higher percentage of total energy coming from fat and a lower percentage coming from carbohydrates and proteins compared to control diet (Sampey et al., 2011). Thus, both CAF and CAFT groups consumed lower protein and carbohydrate and remarkably greater fat compared to CON and CONT groups. Overall, taurine supplementation did not affect food consumption, energy intake and food preferences during gestation and lactation. This is consistent with the findings of previous studies (Li et al., 2013; Li et al., 2015).

Since the total energy intake of dams fed the cafeteria diet was similar to dams fed the control diet throughout pre-gestation, gestation and lactation, total body weights did not differ between cafeteria and control groups at the end of lactation. Some studies reported that consumption of cafeteria diet during 8 weeks before gestation might be failed to trigger significant weight gain (Jacobs et al., 2014; Rossetti et al., 2020). Rossetti et al. (2020) indicated that they maintained feeding cafeteria diet until 14th week of the experiment before mating in order to detect significantly increased body weights in CAF group. Therefore, differences in the duration may lead to contradictory results regarding pre-gestational body weights. Also, at mating no significant differences were observed regarding body weight between groups but previous data showed that at day 20 of gestation cafeteria diet fat dams had greater body fat accumulation which is an essential component of obesity (Akyol et al., 2009). In a previous study, profound adiposity was showed although no difference was observed in terms of body weight between cafeteria and control groups (Buyukdere, Gulec \& Akyol, 2019). Furthermore, the organ weight data at the end of lactation showed that CAF and CAFT animals had significantly increased gonadal and peri-renal fat depots ( $72 \%$ increase in gonadal fat and $77 \%$ in peri-renal fat in CAF). Therefore, it can be suggested that cafeteria diet led to increased adiposity at the end of eight weeks of pre-gestational feeding and this model produced an efficient model of maternal obesity.

Ingestion of cafeteria diet resulted in weight loss during lactation and this was not influenced by taurine supplementation. This can be explained by suggesting that dams fed the cafeteria diet during lactation could invest more energy to milk production and hence their milk could be richer than that the produced by the chow diet-fed lactating rats (Bayol, Farrington \& Stickland, 2007). Indeed, it was demonstrated that milk from cafeteria diet-fed dams contained higher concentration of fat and lower concentration of protein when compared to controls. This may explain the reduced growth rate of the offspring of cafeteria diet fed dams (Pomar et al., 2017). It can be suggested that maternal ingestion of cafeteria diet affected the offspring in a similar setting to the effects of a low protein diet. Lower protein content of the maternal diet could lead to lower body weight at weaning (Bayol, Farrington \& Stickland, 2007; Pomar et al., 
356

357

358

359

360

361

362

363

364

365

366

367

368

369

370

371

372

373

374

375

376

377

378

379

380

381

382

383

384

385

386

387

388

389

390

391

392

393

394

395

2017). In the present study, both male and female CAF and CAFT offspring were leaner than CON and CONT offspring at weaning. In studies conducted with low protein diet models supplementation with taurine did not prevent growth retardation of the offspring during lactation (Boujendar et al., 2002; Merezak et al., 2014). However, another study reported that weaning weights of offspring exposed to obesogenic diet supplemented with taurine was similar to control offspring ( $L i$ et al., 2015). Different dietary exposure models could lead to differential effects on fetal growth and development as protein content of obesogenic diet models exhibited distinct levels of protein.

Despite weight loss during lactation, cafeteria diet fed dams exhibited markedly increased adiposity at the end of lactation. Although CAFT group had lower gonadal and peri-renal fat depots than CAF group; this did not reach to statistical significance in the current study. Thus, taurine supplementation did not decrease gonadal and peri-renal fat pad weights. Supplementation of 5\% (wt/wt) taurine (estimated taurine intake $3 \mathrm{mg} / \mathrm{g}$ body weight/day and 11 $\mathrm{mg} / \mathrm{g}$ body weight/ day respectively) was shown to prevent tissue fat accumulation and obesity with increased energy expenditure (Tsuboyama-Kasaoka et al., 2006; Lin et al., 2013), while high fat diet induced obesity in mice could not be prevented by $1 \%$ taurine treatment (estimated taurine intake $1.7 \mathrm{mg} / \mathrm{g}$ body weight/day) (Murakami, Kondo \& Nagate, 2000). This difference between the studies can be attributable to supplementation dosage and amount of estimated taurine intake. In the current study, estimated taurine intake of CAFT dams was $2.4 \mathrm{mg} / \mathrm{g}$ body weight/day. This result may suggest that higher amount of taurine is required to observe antiobesogenic effects.

Plasma taurine levels were shown to decrease in obesity since taurine synthesis in white adipose tissue is reduced (Tsuboyama-Kasaoka et al., 2006). Also, Rosa et al. (2014) reported that obese women had lower plasma taurine levels than normal weight control group. However, Li et al. (2013 and 2015) indicated that dams fed with maternal obesogenic diets displayed similar plasma taurine concentrations to control dams. These differences might be due to the degree of fat deposition. CAF fed dams exerted decreased plasma taurine levels in this study. Most studies demonstrated that taurine supplementation improved plasma taurine levels in the setting of diet induced obesity (Tsuboyama-Kasaoka et al., 2006; Li et al., 2013; Li et al., 2015). In addition, taurine supplementation resulted in a marked elevation of taurine concentrations in CONT and CAFT dams in the current study.

Many studies have attempted to investigate the influence of maternal cafeteria diet on plasma glucose, insulin, triglyceride and total cholesterol levels. Some have found no differences in glucose and insulin (Crew, Waddell \& Mark, 2016; Crew et al., 2018), triglyceride (Mucellini et al., 2014) and total cholesterol (Jacobs et al., 2014) concentrations as observed in the present study, while others have reported higher glucose and insulin (Holemans et al., 2004; Bouanane et al., 2009) cholesterol (Mucellini et al., 2014) and triglyceride (Chen et al., 2008) concentrations in cafeteria fed dams. The above-cited studies have some differences in the duration and timing of intervention. Therefore, it becomes very difficult to reach a clear conclusion. In the present study, the concentrations of these plasma metabolites were determined

Peer) reviewing PDF | (2020:12:56715:1:2:NEW 24 Mar 2021) 
396

397

398

399

400

401

402

403

404

405

406

407

408

409

410

411

412

413

414

415

416

417

418

419

420

421

422

423

424

425

426

427

428

429

430

431

432

433

434

435

at the end of lactation. Therefore, it is crucial to assess the influence of both cafeteria diet and taurine supplementation on these metabolic parameters during pregnancy in future studies.

Previous reports have shown that plasma leptin concentrations of cafeteria diet-fed dams increased in proportion to body fat mass (Chen et al., 2008; Bouanane et al., 2009; Jacobs et al., 2014). While CAF dams displayed higher plasma leptin concentrations in comparison to control dams, CAFT dams did not display hyperleptinemia in the current study. Similarly, in one study increased plasma leptin levels were observed in maternal obesogenic diet group but not in taurine supplemented group although there was no significant effect of taurine ( $\mathrm{Li}$ et al., 2013). Kim et al. (2012) reported that leptin levels were significantly lower in taurine supplemented group despite similar body weight and epididymal fat mass to control groups. They suggested that additional studies are needed to elucidate the possible effect of taurine on leptin signaling in adipose tissue (Kim et al., 2012). This result is consistent with another report which showed that long term taurine supplementation did not reduce fat tissue but decreased mRNA expression levels of leptin in white adipose tissue (Kim et al., 2019). Decreased circulating adiponectin levels have been demonstrated in high fat and cafeteria diet induced murine models of obesity (Chaolu et al., 2011; Suárez-García et al., 2017). Interestingly, plasma adiponectin concentrations of both CAF and CAFT groups were markedly greater than CON and CONT groups in the present study. Some studies have shown that body weight reduction resulted in increased adiponectin levels in obesity (Yang et al., 2001; Esposito et al., 2003). Therefore, weight loss of CAF and CAFT groups during lactation may have lead to higher adiponectin levels in comparison to CON and CONT groups.

Obesity is an independent risk factor for lipid peroxidation and malondialdehyde is one of the most frequently used indicators of lipid peroxidation (Yesilbursa et al., 2005; Marseglia et al., 2014). High fat and cafeteria diet induced obesity in rats led to elevated malondialdehyde levels in liver in different studies (Noeman, Hamooda \& Baalash, 2011; Abd Elwahab et al. 2017). Similarly, the present study demonstrated that CAF dams had increased plasma malondialdehyde concentrations. Plasma malondialdehyde levels of CAFT dams did not differ from CON and CONT dams, which indicated a partial normalization of the malondialdehyde levels in response to taurine supplementation. It was reported that taurine administration mitigated hepatic oxidative stress through reduction of malondialdehyde levels in the liver of cafeteria fed rats (Abd Elwahab et al. 2017). Also, Ogasawara et al. (1994) reported that taurine inhibited the production of oxidized low density lipoprotein by reacting with malondialdehyde.

Lower energy contribution of protein in the cafeteria diet may induce nitrogen sparing mechanisms including higher intestinal absorbtion of amino acids and excretion of less urinary and fecal nitrogen (Esteve et al., 1993; Oliva et al., 2017). In addition, oxidation of amino acids and urea excretion can decrease (Sabater et al., 2014; Oliva et al., 2017). These mechanisms led to amino acid imbalance and alterations of amino acid concentrations (Llado et al., 1995; Sabater et al., 2014). In the current study, both CAF and CAFT dams displayed higher levels of serine and lower levels of tyrosine compared with control dams. Previous studies reported the effects of cafeteria diet on plasma amino acid concentrations with contradictory results (Salvadó,

Peer] reviewing PDF | (2020:12:56715:1:2:NEW 24 Mar 2021) 
436 Segués \& Arola, 1991; Lladó et al., 1995; Pomar et al., 2019). Offspring suckled by cafeteria 437 diet fed dams exhibited higher circulating levels of serine due to increased hepatic 438 gluconeogenesis (Pomar et al., 2019). However, Salvadó, Segués \& Arola, (1991) demonstrated 439 that serine concentrations was lower in the pups exposed to maternal cafeteria diet during 440 lactation than in the control pups. The low serine concentrations of the pups exposed to maternal 441 cafeteria diet were related to contribution of this amino acid to glucose synthesis in the suckling

442

443

444

445

446

447

448

449

450

451

452

453

454

455

456

457

458

459

460

461

462

463

464

465

466

467

468

469

470

471

472

473

474 offspring. Also, serine was associated with increased growth rate in the pups exposed to maternal cafeteria diet. The amino acid imbalance observed in this study could be related with a possible maternal trade-off to improve growth and development during suckling period.

In the current study no difference was observed in litter size and sex ratio between groups. This is consistent with previous reports (Bayol et al., 2005; Li et al., 2013; Li et al., 2015; Vithayathil et al., 2018). Many studies reported conflicting results about the birth weights of pups exposed to maternal cafeteria diets. Some have found no differences in birth weights (Bayol et al., 2005; Chen et al., 2008; Speight et al., 2017; Kalem et al., 2018) whereas others have reported higher birth weights (Bayol, Farrington \& Stickland, 2007; Sanchez-Blanco et al., 2016; Vithayathil et al., 2018; Cardanes-Perez et al., 2018). Also, a meta regression analysis of animal models investigating the effect of maternal obesogenic diet exposure on birthweight demonstrated that this exposure had no effect on birthweight (Ribaroff et al., 2017). Akyol et al., (2009) reported that exposure to maternal cafeteria diet led to fetal growth restriction, but they showed increased birth weights in their further study (Akyol et al., 2011). These differences might occur due to using different food items in cafeteria diet and duration and time of exposure.

Similar to the results of this study, it was reported that maternal taurine supplementation had no effect on birth weights ( $L i$ et al., 2013). In addition to these outcomes, rise in neonatal mortality was observed in CONT offspring. Similarly, other reports showed that taurine supplementation in the setting of normal pregnancy resulted in increased neonatal mortality ( $\mathrm{Li}$ et al., 2013; Li et al., 2015). There are limited data on possible unfavorable effects of taurine in normal pregnancies and underlying mechanisms have not been elucidated, clearly. Boujendar et al. (2002) reported that taurine provided in dams fed a control diet induced fetal hypoglycaemia and decreased pancreatic and postnatal body weights. Although taurine supplementation in vivo exerted protective effects on pancreatic islets of the offspring from low protein diet fed dams against cytokine toxicity, islet sensitivity of control animals has been increased and pancreatic development was impaired (Boujendar et al., 2002; Merezak et al. 2004). These results demonstrated that the effects of taurine supplementation on pregnancy outcomes were closely associated with maternal nutritional background. Future studies should investigate the possible toxicity of taurine supplementation in control pregnancy outcomes. In fact, one limitation of this study could be giving taurine supplementation during pre-gestation since this design complicates translating the current approach and outcomes to human pregnancy. Instead, taurine supplementation could have been administered after mating but this procedure might have masked the potential regressive influence of taurine on obesity development. Therefore, in 
475 addition to possible toxicity of taurine supplementation in control pregnancy outcomes, a further

476

477

478

479

480

481

482

483

484

485

486

487

488

489

490

491

492

493

494

495

496

497

498

499

500

501

502

503

504

505

506

507

508

\section{Acknowledgements}

510 Conflicts of Interest

511 None

512 Author contribution: A.A. designed and conducted the study. A.K.C. and A.G. performed
513 animal experiments and collected data. A.K.C. and A.G. made laboratory analysis. A.A. and 513

Exposure to maternal high fat diet during gestation may alter the development of various organs and affect several organ systems. These effects differ by the animal model, timing and duration of the high fat diet exposure as well as the offspring's gender (Williams et al., 2014) Previously it has been reported that offspring exposed to maternal obesogenic diet exhibited increased relative heart weight at weaning (Blackmore et al., 2014). This study demonstrated that exposure to maternal cafeteria diet resulted in increased relative heart weight in both male and female CAF offspring at weaning. Taurine supplementation to cafeteria diet normalized relative heart weight. It was shown that taurine supplementation reduced heart weight in hypertensive rats and was associated with decreased cardiac hypertrophy by displaying antioxidant activity (Chahine et al., 2010). Also, both CAFT male and female offspring displayed increased brain weight at weaning. It has been suggested that taurine deficiency might cause decreased proliferation of neural progenitor cell and smaller brain weight in mouse (Shivaraj et al., 2012). In a study of IUGR rats has been reported that prenatal taurine supplementation resulted in increased brain weight above IUGR levels by reducing apoptosis in fetal rat cerebral cells and promotes cerebral cell regeneration (Liu, Liu \& Chen, 2011).

\section{Conclusions}

In conclusion, present data suggest that maternal cafeteria diet led to increased adiposity and malondialdehyde levels, hyperleptinemia and decreased plasma taurine levels. Maternal taurine supplementation did not prevent adiposity but partially normalized cafeteria-induced maternal metabolic dysfunction. Also, taurine supplemented cafeteria diet exerted favorable effects on heart and brain weights of the offspring. The reason why taurine did not have profound protective effects on these metabolic disturbances can be attributable to the amount of taurine consumed by rats. Furthermore, it was showed that taurine supplementation resulted in increased neonatal mortality in control pregnancies, which might be associated with maternal nutritional background. While a few other studies investigated the effects of maternal taurine supplementation on metabolic disturbances induced by high fructose and high fat obesogenic diets ( $\mathrm{Li}$ et al., 2013; $\mathrm{Li}$ et al., 2015), this study reported the influences of taurine supplementation in a model of maternal cafeteria diet for the first time. The long-term effects of maternal taurine supplementation on offspring and adverse maternal effects in normal pregnancies must be further investigated. 
514 A.K.C. did statistical analyses. A.K.C. helped draft the manuscript and interpretation of the data. 515 All authors read and approved the final manuscript.

516 Ethical Standards

517 The authors assert that all procedures contributing to this work comply with the ethical standards 518 of the relevant national guides on the care and use of laboratory animals (rats) and has been 519 approved by the institutional committee (Hacettepe University).

520

521

522

523

524

525

\section{References}

526 Abd Elwahab AH, Ramadan BK, Schaalan MF, Tolba AM. 2017. A novel role of SIRT1/FGF-

527

528 21 in taurine protection against cafeteria diet-induced steatohepatitis in rats. Cellular Physiology

529 and Biochemistry: International Journal of Experimental Cellular Physiology, Biochemistry, and

530

531

532

533

534

535

536

537

538

539

540

541

542

543

544

545

546

547

548

549

550

551

552 Pharmacology 43(2):644-59 DOI: 10.1159/000480649.

Akyol A, Langley-Evans SC, McMullen S. 2009. Obesity induced by cafeteria feeding and pregnancy outcome in the rat. British Journal of Nutrition 102:1601-10 DOI: 10.1017/S0007114509990961.

Akyol A, McMullen S, Langley-Evans SC. 2012. Glucose intolerance associated with early-life exposure to maternal cafeteria feeding is dependent upon post-weaning diet. British Journal of Nutrition 107(7):964-78 DOI: 10.1017/S0007114511003916.

Ayonrinde OT, Oddy WH, Adams LA, Mori TA, Beilin LJ, de Klerk N, Olynyk JK. 2017. Infant nutrition and maternal obesity influence the risk of non-alcoholic fatty liver disease in adolescents. Journal of Hepatology 67: 568-576 DOI: 10.1016/j.jhep.2017.03.029. Badawy AA, Morgan CJ, Turner JA. 2008. Application of the phenomenex EZ:faast trade mark amino acid analysis kit for rapid gas-chromatographic determination of concentrations of plasma tryptophan and its brain uptake competitors. Amino Acids 34:587-596 DOI: 10.1007/s00726007-0012-7.

Bayol SA, Simbi BH, Stickland NC. 2005. A maternal cafeteria diet during gestation and lactation promotes adiposity and impairs skeletal muscle development and metabolism in rat offspring at weaning. The Journal of Physiology 567(Pt3):951-61 DOI: 10.1113/jphysiol.2005.088989.

Bayol SA, Farrington SJ, Stickland NC. 2007. A maternal 'junk food'diet in pregnancy and lactation promotes an exacerbated taste for 'junk food'and a greater propensity for obesity in rat offspring. British Journal of Nutrition 98(4):843-51 DOI: 10.1017/S0007114507812037. Bayol SA, Macharia R, Farrington SJ, Simbi BH, Stickland NC. 2009. Evidence that a maternal "junk food" diet during pregnancy and lactation can reduce muscle force in offspring. European Journal of Nutrition 48:62-5 DOI: 10.1007/s00394-008-0760-5. 
553 Benkalfat NB, Merzouk H, Bouanane S, Merzouk SA, Bellenger J, Gresti J, Tessier C, Narce M.

554

555

556

557

558

559

560

561

562

563

564

565

566

567

568

569

570

571

572

573

574

575

576

577

578

579

580

581

582

583

584

585

586

587

588

589

590

2011. Altered adipose tissue metabolism in offspring of dietary obese rat dams. Clinical Science 121(1):19-28 DOI: 10.1042/CS20100534.

Blackmore HL, Niu Y, Fernandez-Twinn DS, Tarry-Adkins JL, Giussani DA, Ozanne SE. 2014. Maternal diet-induced obesity programs cardiovascular dysfunction in adult male mouse offspring independent of current body weight. Endocrinology 155(10):3970-3980 DOI: $10.1210 / \mathrm{en} .2014-1383$.

Blake-Lamb TL, Locks LM, Perkins ME, Woo Baidal JA, Cheng ER, Taveras EM. 2016. Interventions for Childhood Obesity in the First 1,000 Days. A Systematic Review. American Journal of Preventive Medicine 50:780-789 DOI: 10.1016/j.amepre.2015.11.010.

Bouanane S, Benkalfat NB, Baba Ahmed FZ, Merzouk H, Mokhtari NS, Merzouk SA, Gresti J, Tessier C, Narce M. 2009. Time course of changes in serum oxidant/antioxidant status in overfed obese rats and their offspring. Clinical Science (London, England : 1979) 116(8): 669-80 DOI: $10.1042 / C S 20080413$.

Boujendar S, Reusens B, Merezak S, Ahn MT, Arany E, Hill D, Remacle C. 2002. Taurine supplementation to a low protein diet during foetal and early postnatal life restores a normal proliferation and apoptosis of rat pancreatic islets. Diabetologia 45(6):856-66

DOI: $10.1007 / \mathrm{s} 00125-002-0833-6$.

Buyukdere Y, Gulec A, Akyol A. 2019. Cafeteria diet increased adiposity in comparison to high fat diet in young male rats. PeerJ 5; 7:e6656 DOI: 10.7717/peerj.6656.

Cardenas-Perez RE, Fuentes-Mera L, de la Garza AL, Torre-Villalvazo I, Reyes-Castro LA, Rodriguez-Rocha H, Garcia-Garcia A, Corona-Castillo JC, Tovar AR, Zambrano E, Ortiz-Lopez R, Saville J, Fuller M, Camacho A. 2018. Maternal overnutrition by hypercaloric diets programs hypothalamic mitochondrial fusion and metabolic dysfunction in rat male offspring. Nutrition \& Metabolism 15(1):38 DOI: 10.1186/s12986-018-0279-6.

Chahine R, Hanna J, Bassil C, Rihana N, Mounayar A, Greige H. 2010. Beneficial effect of taurine in spontaneous hypertensive rats: Implication of its antioxidant activity. African Journal of Pharmacy and Pharmacology 4(12):874-877.

Chaolu H, Asakawa A, Ushikai M, Li YX, Cheng KC, Li JB, Zoshiki T, Terashi M, Tanaka C, Atsuchi K, Sakoguchi T, Tsai M, Amitani H, Horiuchi M, Takeuchi T, Inui A. 2011. Effect of exercise and high-fat diet on plasma adiponectin and nesfatin levels in mice. Experimental and Therapeutic Medicine 2(2):369-73 DOI: 10.3892/etm.2011.199.

Chen H, Simar D, Lambert K, Mercier J, Morris MJ. 2008. Maternal and postnatal overnutrition differentially impact appetite regulators and fuel metabolism. Endocrinology 149(11):5348-56 DOI: $10.1210 / \mathrm{en} .2008-0582$.

Crew RC, Waddell BJ, Mark PJ. 2016. Maternal obesity induced by a 'cafeteria' diet in the rat does not increase inflammation in maternal, placental or fetal tissues in late gestation. Placenta 39:33-40 DOI: 10.1016/j.placenta.2016.01.002.

Peer) reviewing PDF | (2020:12:56715:1:2:NEW 24 Mar 2021) 
591 Crew RC, Waddell BJ, Maloney SK, Mark PJ. 2018. Diet-induced obesity reduces core body 592 temperature across the estrous cycle and pregnancy in the rat. Chronobiology International 593 35(8): 1077-87 DOI: 10.1080/07420528.2018.1458035

594 Daniel ZC, Akyol A, McMullen S, Langley-Evans SC. 2014. Exposure of neonatal rats to 595 maternal cafeteria feeding during suckling alters hepatic gene expression and DNA methylation 596 in the insulin signalling pathway. Genes and Nutrition 9(1):365 DOI: 10.1007/s12263-013-03655973.

598 Desai M, Jellyman JK, Han G, Beall M, Lane RH, Ross MG. 2014. Maternal obesity and high599 fat diet program offspring metabolic syndrome. American Journal of Obstetrics and Gynecology 600 211(3):237.e1-237.e13 DOI: 10.1016/j.ajog.2014.03.025.

601 Dias-Rocha CP, Almeida MM, Santana EM, Costa JCB, Franco JG, Pazos-Moura CC,

602 Trevenzoli IH. 2018. Maternal high-fat diet induces sex-specific endocannabinoid system

603 changes in newborn rats and programs adiposity, energy expenditure and food preference in 604 adulthood. Journal of Nutritional Biochemistry 51:56-68 DOI: 10.1016/j.jnutbio.2017.09.019.

605 Esposito K, Pontillo A, Di Palo C, Giugliano G, Masella M, Marfella R, Giugliano D. 2003.

606 Effect of weight loss and lifestyle changes on vascular inflammatory markers in obese women: a 607 randomized trial. JAMA 289(14):1799-804 DOI: 10.1001/jama.289.14.1799.

608 Esteve M, Rafecas I, Fernández-López JA, Remesar X, Alemany M. 1993. Dietary amino acid 609 balances in young Wistar rats fed a cafeteria diet. Biochemistry and Molecular Biology 610 International 29(6):1069-81.

611 Ferro Cavalcante TC, Marcelino da Silva AA, Lira MC, do Amaral Almeida LC, Marques AP, 612 do Nascimento E. 2014. Early exposure of dams to a westernized diet has long-term

613 consequences on food intake and physiometabolic homeostasis of the rat offspring. International 614 Journal of Food Sciences and Nutrition 65(8):989-93 DOI: 10.3109/09637486.2014.950208.

615 Fisher SC, Kim SY, Sharma AJ, Rochat R, Morrow B. 2013. Is obesity still increasing among 616 pregnant women? Prepregnancy obesity trends in 20 states, 2003-2009. Preventive Medicine 617 56:372-8 DOI: 10.1016/j.ypmed.2013.02.015.

618 George G, Draycott SAV, Muir R, Clifford B, Elmes MJ, Langley-Evans SC. 2019. The impact 619 of exposure to cafeteria diet during pregnancy or lactation on offspring growth and adiposity 620 before weaning. Scientific Reports 9(1):14173 DOI: 10.1038/s41598-019-50448-x.

621 Gugusheff JR, Bae SE, Rao A, Clarke IJ, Poston L, Taylor PD, Coen CW, Muhlhausler BS. 622 2016. Sex and age-dependent effects of a maternal junk food diet on the mu-opioid receptor in 623 rat offspring. Behavioral Brain Research 15(301):124-31 DOI: 10.1016/j.bbr.2015.12.027.

624 Holemans K, Caluwaerts S, Poston L, Van Assche FA. 2004. Diet-induced obesity in the rat: a 625 model for gestational diabetes mellitus. American Journal of Obstetrics and Gynecology

626 190(3):858-65 DOI: 10.1016/j.ajog.2003.09.025.

627 Ince S, Arslan-Acaroz D, Demirel HH, Varol N, Ozyurek HA, Zemheri F, Kucukkurt I. 2017.

628 Taurine alleviates malathion induced lipid peroxidation, oxidative stress, and proinflammatory 629 cytokine gene expressions in rats. Biomedicine \& Pharmacotherapy 96:263-268.

630 DOI: 10.1016/j.biopha.2017.09.141. 
631 Jacobs S, Teixeira DS, Guilherme C, da Rocha CF, Aranda BC, Reis AR, de Souza MA, Franci 632 CR, Sanvitto GL. 2014. The impact of maternal consumption of cafeteria diet on reproductive 633 function in the offspring. Physiology \& Behavior 129:2806 DOI: 10.1016/j.physbeh.2014.03.003 634 Kalem Z, Namli Kalem M, Anadol E, Bakirarar B, Yilmaz C, Elmas C, Yalcinkaya P, Ruso H, 635 Gurgan T. 2018. Maternal Nutrition and Reproductive Functions of Female and Male Offspring. 636 Reproduction 156(4):353-64 DOI: 10.1530/REP-18-0070.

637 Kim KS, Oh DH, Kim JY, Lee BG, You JS, Chang KJ, Chung HJ, Yoo MC, Yang HI, Kang JH, 638 Hwang YC, Ahn KJ, Chung HY, Jeong IK. 2012. Taurine ameliorates hyperglycemia and 639 dyslipidemia by reducing insulin resistance and leptin level in Otsuka Long-Evans Tokushima 640 fatty (OLETF) rats with long-term diabetes. Experimental \& Molecular Medicine 44(11):665-73 641 DOI: $10.3858 / \mathrm{emm} .2012 .44 .11 .075$.

642 Kim KS, Jang MJ, Fang S, Yoon SG, Kim IY, Seong JK, Yang HI, Hahm DH. 2019. Anti643 obesity effect of taurine through inhibition of adipogenesis in white fat tissue but not in brown

644 fat tissue in a high-fat diet-induced obese mouse model. Amino Acids 51(2):245-54

645 DOI: 10.1007/s00726-018-2659-7.

646 Larsen LH, Sandø-Pedersen S, Ørstrup LKH, Grunnet N, Quistorff B, Mortensen OH. 2017.

647 Gestational Protein Restriction in Wistar Rats; Effect of Taurine Supplementation on Properties

648 of Newborn Skeletal Muscle. Advances in Experimental Medicine and Biology 975:413-433

649 DOI: 10.1007/978-94-024-1079-2_34.

650 Li M, Reynolds CM, Sloboda DM, Gray C, Vickers MH. 2013. Effects of taurine

651 supplementation on hepatic markers of inflammation and lipid metabolism in mothers and

652 offspring in the setting of maternal obesity. PLoS One 8:e76961

653 DOI: 10.1371/journal.pone.0076961.

654 Li M, Reynolds CM, Sloboda DM, Gray C, Vickers MH. 2015. Maternal taurine

655 supplementation attenuates maternal fructose-induced metabolic and inflammatory dysregulation 656 and partially reverses adverse metabolic programming in offspring. Journal of Nutritional

657 Biochemistry 26:267-76 DOI: 10.1016/j.jnutbio.2014.10.015.

658 Lin S, Hirai S, Yamaguchi Y, Goto T, Takahashi N, Tani F, Mutoh C, Sakurai T, Murakami S,

659 Yu R, Kawada T. 2013. Taurine improves obesity-induced inflammatory responses and

660 modulates the unbalanced phenotype of adipose tissue macrophages. Molecular Nutrition and

661 Food Research 57(12):2155-65 DOI: 10.1002/mnfr.201300150.

662 Liu J, Liu L, Chen H. 2011. Antenatal taurine supplementation for improving brain ultrastructure 663 in fetal rats with intrauterine growth restriction. Neuroscience 181:265-270

664 DOI: 10.1016/j.neuroscience.2011.02.056.

665 Lladó I, Picó C, Palou A, Pons A. 1995. Protein and amino acid intake in cafeteria fed obese rats.

666 Physiology \& Behavior 58(3):513-9 DOI: 10.1016/0031-9384(95)00081-s.

667 Marseglia L, Manti S, D'Angelo G, Nicotera A, Parisi E, Di Rosa G, Gitto E, Arrigo T. 2014.

668 Oxidative stress in obesity: a critical component in human diseases. International Journal of

669 Molecular Sciences 16(1): 378-400 DOI: 10.3390/ijms16010378. 
670 Merezak S, Reusens B, Renard A, Goosse K, Kalbe L, Ahn MT, Tamarit-Rodriguez J, Remacle

671 C. 2004. Effect of maternal low-protein diet and taurine on the vulnerability of adult Wistar rat

672 islets to cytokines. Diabetologia 47(4):669-75 DOI: 10.1007/s00125-004-1357-z.

673 Mucellini AB, Goularte JF, de Araujo da Cunha AC, Caceres RC, Noschang C, da Silva Benetti

674 C, Silveira PP, Sanvitto GL. 2014. Effects of exposure to a cafeteria diet during gestation and

675 after weaning on the metabolism and body weight of adult male offspring in rats. British Journal

676 of Nutrition 111(8): 1499-506 DOI: 10.1017/S0007114513003838

677 Murakami S, Kondo Y, Nagate T. 2000. Effects of long-term treatment with taurine in mice fed a 678 high-fat diet: improvement in cholesterol metabolism and vascular lipid accumulation by taurine.

679 Advances in Experimental Medicine and Biology 483:177-86 DOI: 10.1007/0-306-46838-7_19.

680 Nagl M, Lehnig F, Stepan H, Wagner B, Kersting A. 2017. Associations of childhood

681 maltreatment with pre-pregnancy obesity and maternal postpartum mental health: a cross-

682 sectional study. BMC Pregnancy Childbirth 17:391 DOI: 10.1186/s12884-017-1565-4.

$683 \mathrm{Ng} \mathrm{M}$, Fleming T, Robinson M, Thomson B, Graetz N, Margono C, Mullany EC, Biryukov S, 684 Abbafati C, Abera SF, Abraham JP, Abu-Rmeileh NM, Achoki T, AlBuhairan FS, Alemu ZA, 685 Alfonso R, Ali MK, Ali R, Guzman NA, Ammar W, Anwari P, Banerjee A, Barquera S, Basu S, 686 Bennett DA, Bhutta Z, Blore J, Cabral N, Nonato IC, Chang JC, Chowdhury R, Courville KJ, 687 Criqui MH, Cundiff DK, Dabhadkar KC, Dandona L, Davis A, Dayama A, Dharmaratne SD, 688 Ding EL, Durrani AM, Esteghamati A, Farzadfar F, Fay DF, Feigin VL, Flaxman A, 689 Forouzanfar MH, Goto A, Green MA, Gupta R, Hafezi-Nejad N, Hankey GJ, Harewood HC, 690 Havmoeller R, Hay S, Hernandez L, Husseini A, Idrisov BT, Ikeda N, Islami F, Jahangir E, 691 Jassal SK, Jee SH, Jeffreys M, Jonas JB, Kabagambe EK, Khalifa SE, Kengne AP, Khader YS, 692 Khang YH, Kim D, Kimokoti RW, Kinge JM, Kokubo Y, Kosen S, Kwan G, Lai T, Leinsalu M, 693 Li Y, Liang X, Liu S, Logroscino G, Lotufo PA, Lu Y, Ma J, Mainoo NK, Mensah GA, 694 Merriman TR, Mokdad AH, Moschandreas J, Naghavi M, Naheed A, Nand D, Narayan KM, 695 Nelson EL, Neuhouser ML, Nisar MI, Ohkubo T, Oti SO, Pedroza A, Prabhakaran D, Roy N, 696 Sampson U, Seo H, Sepanlou SG, Shibuya K, Shiri R, Shiue I, Singh GM, Singh JA, Skirbekk 697 V, Stapelberg NJ, Sturua L, Sykes BL, Tobias M, Tran BX, Trasande L, Toyoshima H, van de 698 Vijver S, Vasankari TJ, Veerman JL, Velasquez-Melendez G, Vlassov VV, Vollset SE, Vos T, 699 Wang C, Wang X, Weiderpass E, Werdecker A, Wright JL, Yang YC, Yatsuya H, Yoon J, Yoon 700 SJ, Zhao Y, Zhou M, Zhu S, Lopez AD, Murray CJ, Gakidou E. 2014. Global, regional, and 701 national prevalence of overweight and obesity in children and adults during 1980-2013: a

702

703

704

705

706

707 systematic analysis for the Global Burden of Disease Study 2013. Lancet 384: 766-81 DOI: 10.1016/S0140-6736(14)60460-8. Nielsen CU, Bjerg M, Ulaganathan N, Holm R. 2017. Oral and intravenous pharmacokinetics of taurine in sprague-dawley rats: the influence of dose and the possible involvement of the protoncoupled amino acid transporter, PAT1, in oral taurine absorption. Physiological Reports 5(19):e13467 DOI: 10.14814/phy2.13467. 
708 Noeman SA, Hamooda HE, Baalash AA. 2011. Biochemical study of oxidative stress markers in 709 the liver, kidney and heart of high fat diet induced obesity in rats. Diabetology \& Metabolic 710 Syndrome 3(1):17 DOI: 10.1186/1758-5996-3-17.

711 Ogasawara M, Nakamura T, Koyama I, Nemoto M, Yoshida T. 1993. Reactivity of taurine with 712 aldehydes and its physiological role. Chemical \& Pharmaceutical Bulletin 41(12):2172-2175

713 DOI: $10.1248 / \mathrm{cpb} .41 .2172$.

714 Oliva L, Aranda T, Caviola G, Fernández-Bernal A, Alemany M, Fernández-López JA, Remesar 715 X. 2017. In rats fed high-energy diets, taste, rather than fat content, is the key factor increasing 716 food intake: a comparison of a cafeteria and a lipid-supplemented standard diet. PeerJ 5:e3697

717 DOI: 10.7717/peerj.3697.

718 Oliva L, Alemany M, Remesar X, Fernández-López JA. 2019. The Food Energy/Protein Ratio

719 Regulates the Rat Urea Cycle but Not Total Nitrogen Losses. Nutrients 11(2):316

720 DOI: 10.3390/nu11020316.

721 Pomar CA, van Nes R, Sánchez J, Picó C, Keijer J, Palou A. 2017. Maternal consumption of a 722 cafeteria diet during lactation in rats leads the offspring to a thin-outside-fat-inside phenotype.

723 International Journal of Obesity 41(8):1279-1287 DOI: 10.1038/ijo.2017.42.

724 Pomar CA, Kuda O, Kopecky J, Rombaldova M, Castro H, Picó C, Sánchez J, Palou A. 2019.

725 Alterations in plasma acylcarnitine and amino acid profiles may indicate poor nutrition during

726 the suckling period due to maternal intake of an unbalanced diet and may predict later metabolic

727 dysfunction. FASEB Journal : Official Publication of The Federation of American Societies for

728 Experimental Biology 33(1):796-807 DOI: 10.1096/fj.201800327RR.

729 Popkin BM. Nutrition Transition and the Global Diabetes Epidemic. 2015. Current Diabetes

730 Reports 15:64 DOI: 10.1007/s11892-015-0631-4.

731 Raipuria M, Hardy GO, Bahari H, Morris MJ. 2015. Maternal obesity regulates gene expression

732 in the hearts of offspring. Nutrition, Metabolism, and Cardiovascular Diseases 25:881-8

733 DOI: 10.1016/j.numecd.2015.05.011.

734 Rashid K, Das J, Sil PC. 2013. Taurine ameliorate alloxan induced oxidative stress and intrinsic 735 apoptotic pathway in the hepatic tissue of diabetic rats. Food and Chemical Toxicology 51:31773629 DOI: 10.1016/j.fct.2012.10.007.

737 Ribaroff GA, Wastnedge E, Drake AJ, Sharpe RM, Chambers TJG. 2017. Animal models of 738 maternal high fat diet exposure and effects on metabolism in offspring: a meta-regression 739 analysis. Obesity Reviews 18(6):673-686 DOI: 10.1111/obr.12524.

740 Rosa FT, Freitas EC, Deminice R, Jordão AA, Marchini JS. 2014. Oxidative stress and

741 inflammation in obesity after taurine supplementation: a double-blind, placebo-controlled study.

742 European Journal of Nutrition 53(3):823-30 DOI: 10.1007/s00394-013-0586-7.

743 Rossetti MF, Schumacher R, Gastiazoro MP, Lazzarino GP, Andreoli MF, Stoker C, Varayoud J, 744 Ramos JG. 2020. Epigenetic Dysregulation of Dopaminergic System by Maternal Cafeteria Diet 745 During Early Postnatal Development. Neuroscience 1(424): $12-23$

746 DOI: 10.1016/j.neuroscience.2019.09.016. 
747 Sabater D, Agnelli S, Arriarán S, Fernández-López JA, Romero Mdel M, Alemany M, Remesar

748 X. 2014. Altered nitrogen balance and decreased urea excretion in male rats fed cafeteria diet are

749 related to arginine availability. BioMed Research International 2014:959420

750 DOI: $10.1155 / 2014 / 959420$.

751 Salvadó MJ, Segués T, Arola L. 1991. Postnatal development of plasma amino acids in

752 hyperphagic rats. Annals of Nutrition and Metabolism 35(4): 242-248 DOI: 10.1159/000177652.

753 Sampey BP, Vanhoose AM, Winfield HM, Freemerman AJ, Muehlbauer MJ, Fueger PT,

754 Newgard CB, Makowski L. 2011. Cafeteria diet is a robust model of human metabolic syndrome

755 with liver and adipose inflammation: comparison to high-fat diet. Obesity (Silver Spring)

756 19:1109-17 DOI: 10.1038/oby.2011.18.

757 Sánchez-Blanco C, Amusquivar E, Bispo K, Herrera E. 2016. Influence of cafeteria diet and fish

758 oil in pregnancy and lactation on pups' body weight and fatty acid profiles in rats. European

759 Journal of Nutrition 55(4):1741-53 DOI: 10.1007/s00394-015-0992-0.

760 Sheen JM, Yu HR, Tain YL, Tsai WL, Tiao MM, Lin IC, Tsai CC, Lin YJ, Huang LT. 2018.

761 Combined maternal and postnatal high-fat diet leads to metabolic syndrome and is effectively

762 reversed by resveratrol: a multiple-organ study. Scientific Reports 8(1):5607

763 DOI: 10.1038/s41598-018-24010-0.

764 Shivaraj MC, Marcy G, Low G, Ryu JR, Zhao X, Rosales FJ, Goh EL. 2012. Taurine induces

765 proliferation of neural stem cells and synapse development in the developing mouse brain. PLoS

766 One 7(8): e42935 DOI: 10.1371/journal.pone.0042935.

767 Son JS, Liu X, Tian Q, Zhao L, Chen Y, Hu Y, Chae SA, de Avila JM, Zhu MJ, Du M. 2019.

768 Exercise prevents the adverse effects of maternal obesity on placental vascularization and fetal

769 growth. The Journal of Physiology 597(13):3333-3347 DOI: 10.1113/JP277698.

770 Speight A, Davey WG, McKenna E, Voigt JW. 2017. Exposure to a maternal cafeteria diet

771 changes open-field behaviour in the developing offspring. International Journal of

772 Developmental Neuroscience 57:34-40 DOI: 10.1016/j.ijdevneu.2016.12.005.

773 Stuebe AM, Rich-Edwards JW. 2009. The reset hypothesis: lactation and maternal metabolism.

774 American Journal of Perinatology 26(1):81-8 DOI: 10.1055/s-0028-1103034.

775 Suárez-García S, Del Bas JM, Caimari A, Escorihuela RM, Arola L, Suárez M. 2017. Impact of

776 a cafeteria diet and daily physical training on the rat serum metabolome. PLoS One

777 12(2):e0171970 DOI: 10.1371/journal.pone.0171970.

778 Tsuboyama-Kasaoka N, Shozawa C, Sano K, Kamei Y, Kasaoka S, Hosokawa Y, Ezaki O. 2006.

779 Taurine (2-aminoethanesulfonic acid) deficiency creates a vicious circle promoting obesity.

780 Endocrinology 147(7):3276-84 DOI: 10.1210/en.2005-1007.

781 Vithayathil MA, Gugusheff JR, Ong ZY, Langley-Evans SC, Gibson RA, Muhlhausler

782 BS. 2018. Exposure to maternal cafeteria diets during the suckling period has greater effects on

783 fat deposition and Sterol Regulatory Element Binding Protein-1c (SREBP-1c) gene expression in

784 rodent offspring compared to exposure before birth. Nutrition \& Metabolism 15:17

785 DOI: $10.1186 / \mathrm{s} 12986-018-0253-3$. 
786 Williams L, Seki Y, Vuguin PM, Charron MJ. 2014. Animal models of in utero exposure to a

787 high fat diet: a review. Biochimica et Biophysica Acta 1842(3):507-519

788 DOI: 10.1016/j.bbadis.2013.07.006.

789 Yang WS, Lee WJ, Funahashi T, Tanaka S, Matsuzawa Y, Chao CL, Chen CL, Tai TY, Chuang

790 LM. 2001. Weight reduction increases plasma levels of an adipose-derived anti-inflammatory

791 protein, adiponectin. The Journal of Clinical Endocrinology and Metabolism 86(8):3815-9

792 DOI: 10.1210/jcem.86.8.7741.

793 Yesilbursa D, Serdar Z, Serdar A, Sarac M, Coskun S, Jale C. 2005. Lipid peroxides in obese

794 patients and effects of weight loss with orlistat on lipid peroxides levels. International Journal of

795 Obesity 29(1):142-5 DOI: 10.1038/sj.ijo.0802794.

796 Zheng Y, Qu H, Wang D, Li S, Zhang C, Piao F. 2017. Protection of Taurine Against Arsenic-

797 Induced DNA Damage of Mice Kidneys. Advances in Experimental Medicine and Biology

798 975:917-927 DOI: 10.1007/978-94-024-1079-2_73. 
Figure 1

Study design

Control diet (CON); control diet with $1.5 \%$ taurine in drinking water (CONT); cafeteria diet (CAF); cafeteria diet with $1.5 \%$ taurine in drinking water (CAFT). Values for $n$ show the number of successful pregnancies in each group.

\section{Pre-pregnancy (8 weeks) Pregnancy Lactation}

CON, $n=6$
CONT, $n=7$
CAF, $n=7$
CAFT, $n=7$
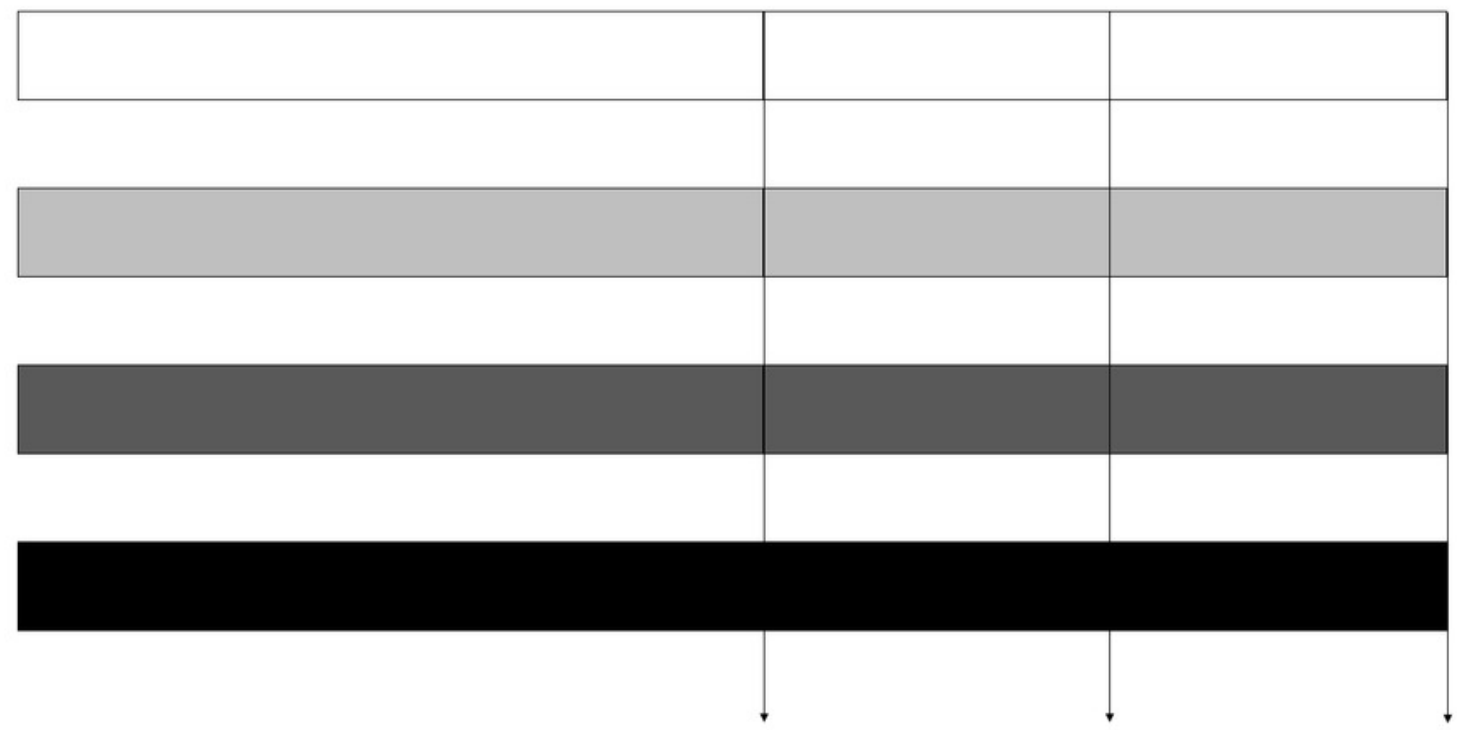

Mating

Birth Weaning 


\section{Figure 2}

Maternal water and taurine intakes

(a) Water intake before and during pregnancy in rats fed a CON, control chow diet; CONT, control chow diet supplemented with taurine; CAF, cafeteria diet; CAFT, cafeteria diet supplemented with taurine. Values are means, with standard errors represented by vertical bars, for $n=6$ (CON); $n=7$ (CONT, CAF and CAFT). Water intake during the pre-gestational period was significantly lower in the CAF and CAFT fed animals (effect of diet, $\mathrm{P}<0.001$ ). Water intake during the gestational period was significantly lower in the CAF and CAFT fed animals (effect of diet and study weeks, $\mathrm{P}<0.001$ ). Water intake during the lactation period was significantly lower in the CAF and CAFT fed animals (effect of diet, $\mathrm{P}<0.001$; study weeks $\mathrm{P}<0.001$; interaction between diet*study weeks, $\mathrm{P}<0.001)$. (b) Taurine intake $(\mathrm{mg} / \mathrm{g}$ body weight/day) before and during pregnancy in rats fed a CONT, control chow diet supplemented with taurine; CAFT, cafeteria diet supplemented with taurine. Values are means, with standard errors represented by vertical bars, for $n=7$ (CONT and CAFT). Taurine intake during the pre-gestational period was significantly lower in the CAFT fed animals (effect of diet, $\mathrm{P}<0.001)$. Taurine intake during the gestational period was significantly lower in the CAFT fed animals (effect of diet and study weeks, $\mathrm{P}<0.001$ ). Taurine intake during the lactation period was significantly lower in the CAFT fed animals (effect of diet, $\mathrm{P}<0.001$; study weeks $\mathrm{P}<0.001$; interaction between diet*study weeks, $\mathrm{P}<0.001)^{\mathrm{a}, \mathrm{b}}$ Mean values with unlike superscript letters were significantly different $(P<0.001)$ 
(a)

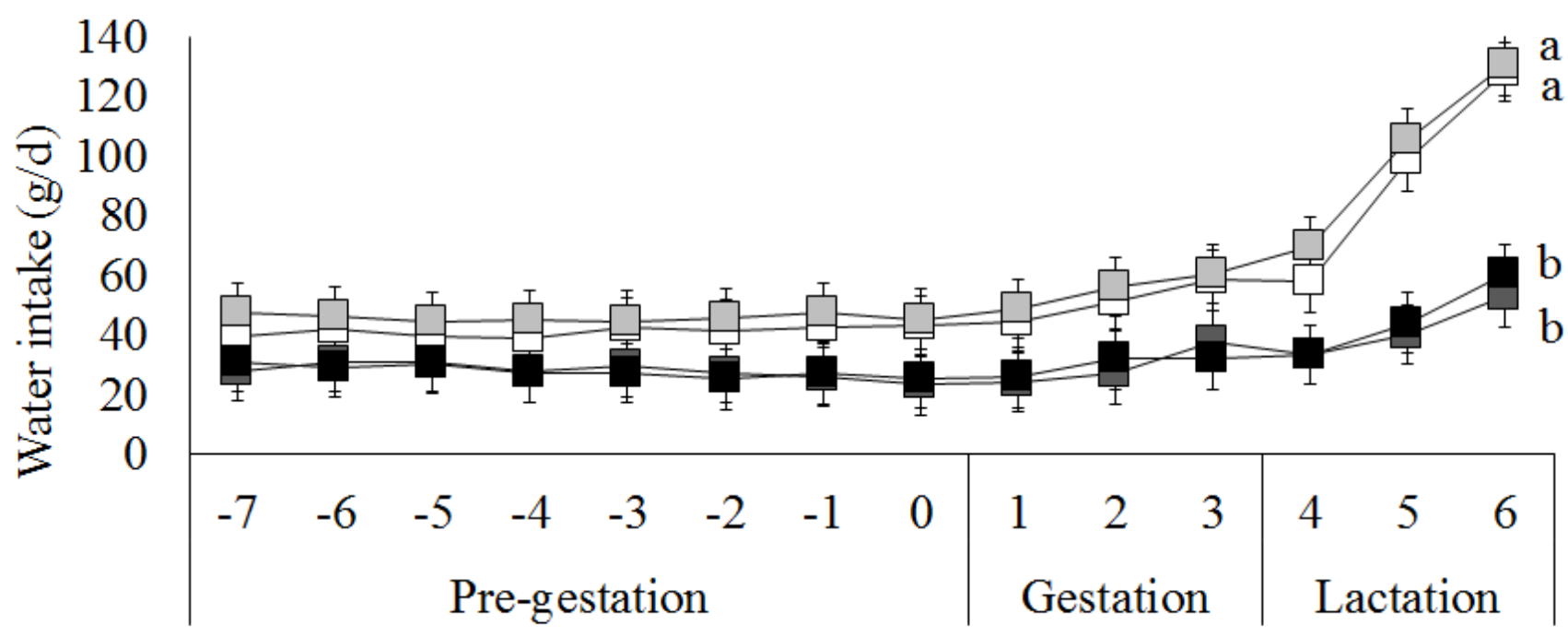

Study weeks

$\square \mathrm{CON} \quad \square \mathrm{CONT} \quad \square \mathrm{CAF} \quad \mathrm{CAFT}$

(b)

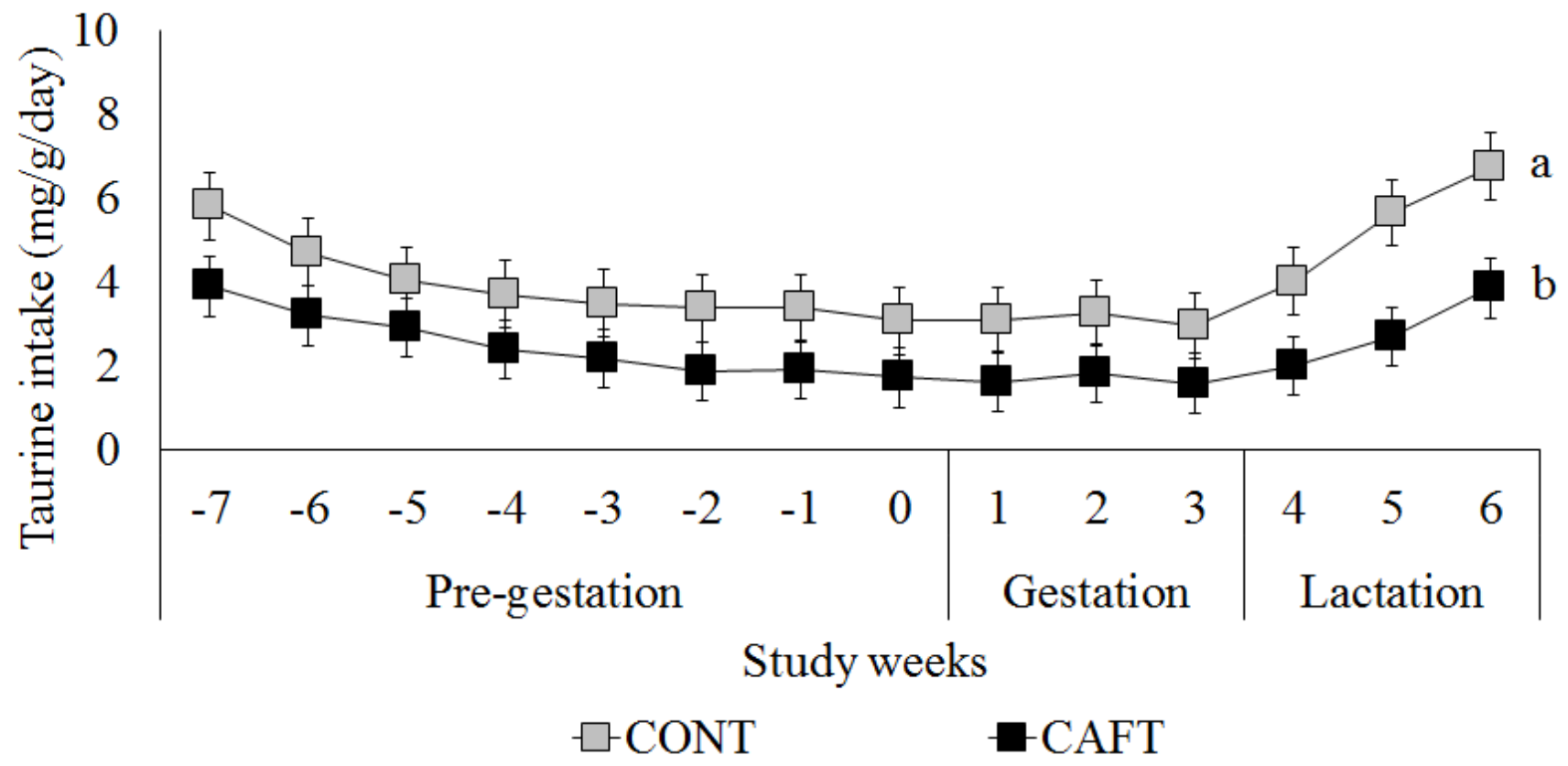




\section{Figure 3}

Body weight changes before and during pregnancy

CON, control chow diet; CONT, control chow diet supplemented with taurine; CAF, cafeteria diet; CAFT, cafeteria diet supplemented with taurine. Values are means, with standard errors represented by vertical bars, for $n=6$ (CON); $n=7$ (CONT, CAF and CAFT). A significant interaction between diet and study weeks influenced body weight during pre-gestational period (interaction between diet*study weeks, $\mathrm{P}=0.002$ ). Body weight during the gestational period did not differ between groups (effect of diet, $\mathrm{P}=0.369$; study weeks, $\mathrm{P}<0.001$ ). Body weight during the lactation period was significantly lower in the CAFT fed animals than CONT fed animals (effect of diet, $P=0.035$; interaction between diet*study weeks, $P<0.001$ ). ${ }^{a, b}$ Mean values with unlike superscript letters were significantly different $(P<0.001)$ 


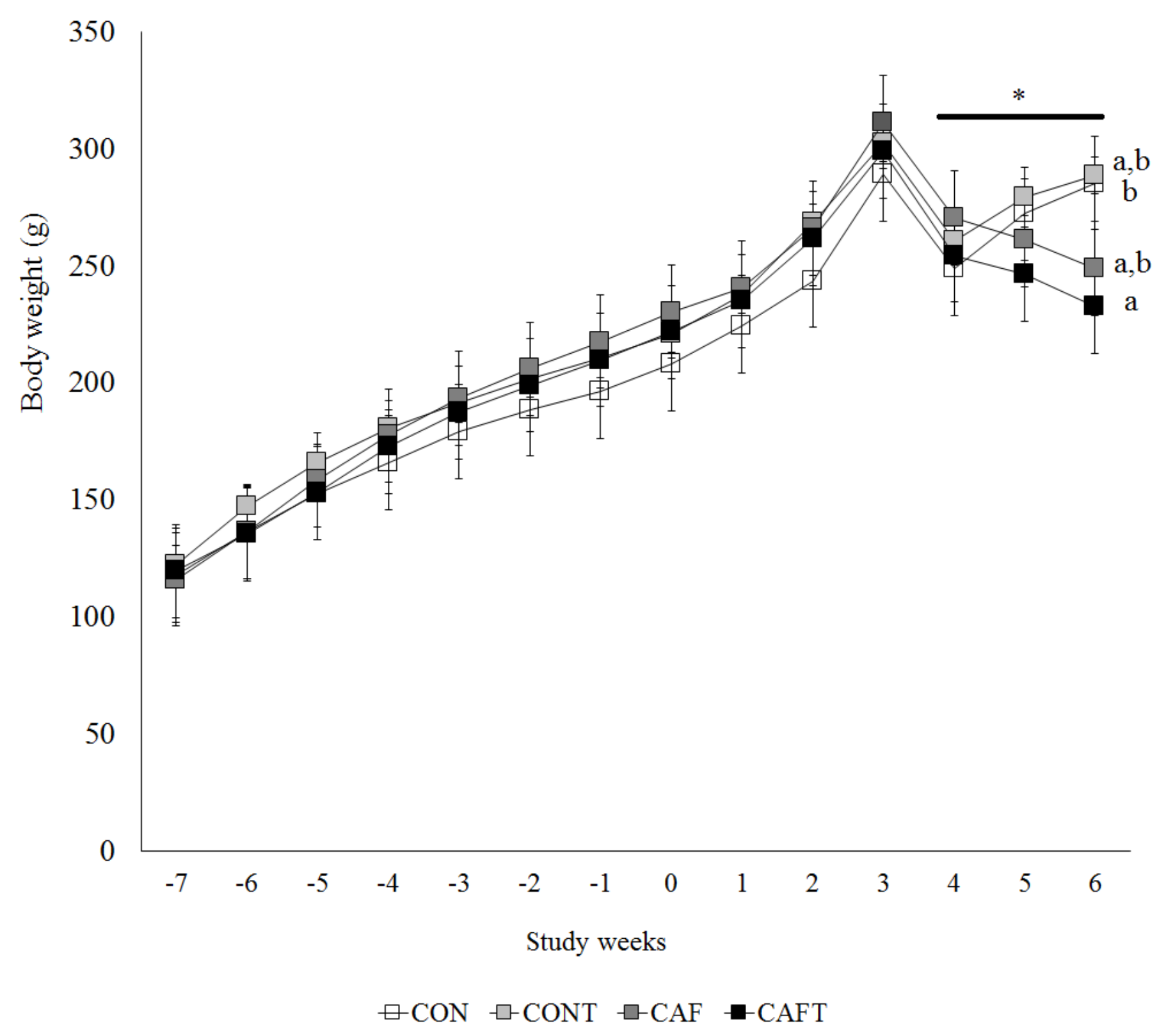




\section{Figure 4}

Body weight changes of offspring during lactation period

CON, rats fed the control chow diet before and during pregnancy; CONT, rats fed the control chow diet supplemented with taurine before and during pregnancy; CAF, rats fed the cafeteria diet before and during pregnancy; CAFT, rats fed the cafeteria diet supplemented with taurine before and during pregnancy. (a) Body weight changes of male offspring during lactation period. (b) Body weight changes of female offspring during lactation period. Values are means, with standard errors represented by vertical bars, for $n=18$ (CON, males), $n=28$ (CON, female), $n=20$ (CONT, male), $n=25$ (CONT, female), $n=25$ (CAF, male), $n=22$ (CAF, female), $n=27$ (CAFT, male) and $n=26$ (CAFT, female). Body weight was significantly influenced by maternal diet $(P<0.001)$, study weeks $(P<0.001)$ and interaction of maternal diet and study weeks $(P<0.001)$. Body weight during the lactation period was significantly lower in CAF and CAFT offspring than CON and CONT offspring (effect of diet, $\mathrm{P}<0.001$ ). ${ }^{a, b, c}$ Mean values with unlike superscript letters were significantly different $(P<0.001)$ 
(a)

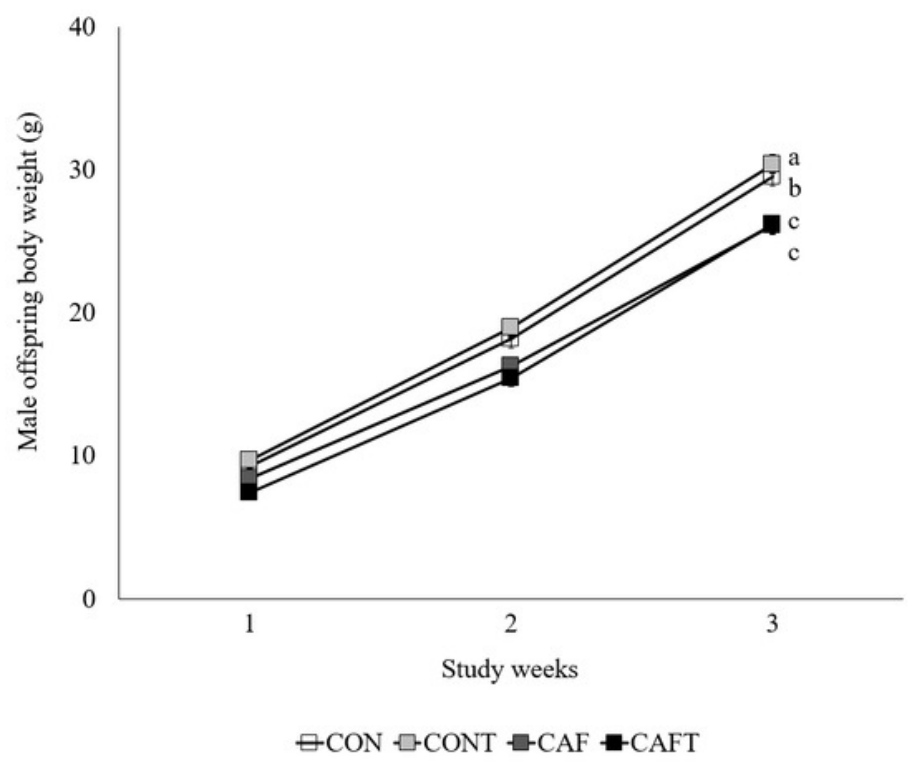

(b)

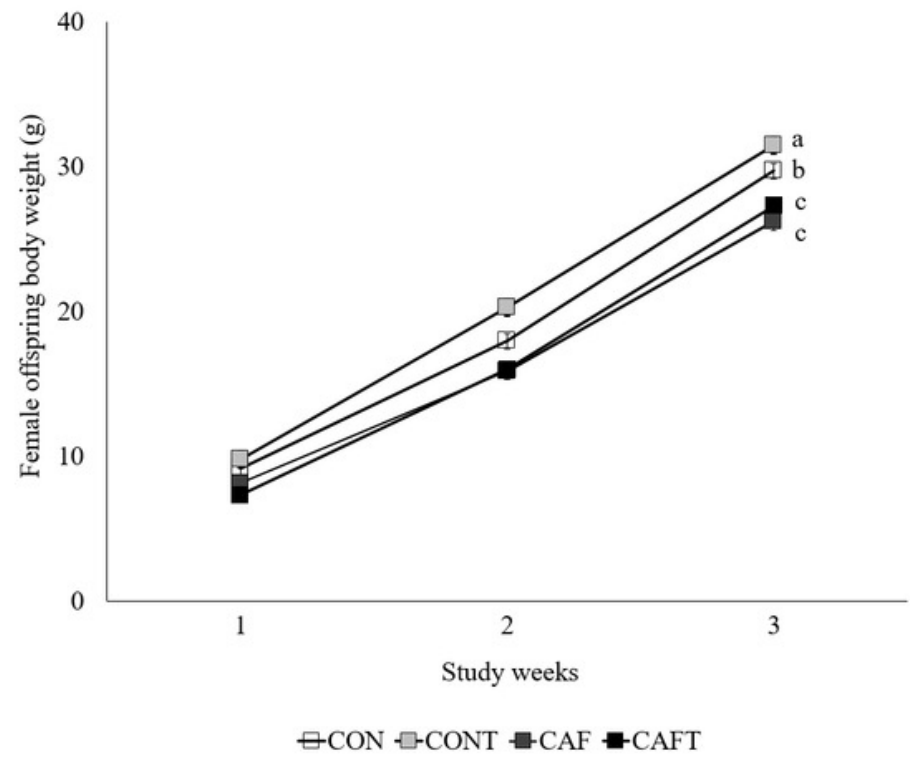




\section{Table $\mathbf{1}$ (on next page)}

Average daily maternal intakes of energy and nutrients per body weight during the pregestational, gestational and lactation periods

Mean values with their standard errors, $n=6$ (CON), $n=7$ (CONT, CAF and CAFT). CON, control chow diet; CONT, control chow diet supplemented with taurine; CAF, cafeteria diet; CAFT, cafeteria diet supplemented with taurine. † Diet and study weeks significantly influenced fat intake during pre-gestation (Diet, $\mathrm{P}<0.001$; study weeks, $\mathrm{P}<0.001$ ), gestation (Diet, $\mathrm{P}<0.001$; study weeks, $\mathrm{P}=0.001$ ) and lactation (Diet, $\mathrm{P}<0.001$; study weeks, $\mathrm{P}<0.001$ ). A significant interaction between diet and study weeks also influenced fat intake during pre-gestation, gestation and lactation $(P<0.05)$. § Diet and study weeks significantly influenced protein intake during pre-gestation (Diet, $\mathrm{P}<0.001$; study weeks, $\mathrm{P}<0.001$ ), gestation (Diet, $\mathrm{P}<0.001$; study weeks, $\mathrm{P}<0.001$ ) and lactation (Diet, $\mathrm{P}<0.001$; study weeks, $\mathrm{P}<0.001$ ). A significant interaction between diet and study weeks also influenced protein intake during gestation and lactation $(P<0.05)$. $¥$ Diet and study weeks significantly influenced carbohydrate intake during pre-gestation (Diet, $\mathrm{P}=0.001$; study weeks, $\mathrm{P}<0.001$ ), gestation (Diet, $\mathrm{P}<0.001$; study weeks, $\mathrm{P}<0.001$ ) and lactation (Diet, $\mathrm{P}<0.001$; study weeks, $\mathrm{P}<0.001$ ). A significant interaction between diet and study weeks also influenced carbohydrate intake during gestation and lactation $(P<0.01)$. $¥$ Diet and study weeks significantly influenced sodium intake during pre-gestation (Diet, $\mathrm{P}<0.001$; study weeks, $\mathrm{P}<0.001$ ) and gestation (Diet, $P=0.008$; study weeks, $P=0.021$ ). A significant interaction between diet and study weeks also influenced sodium intake during pre-gestation (interaction between diet*study weeks, $P<0.05)$. A significant interaction between diet and study weeks influenced sodium intake during lactation (interaction between diet*study weeks, $\mathrm{P}<0.05$ ). ${ }^{\mathrm{a}, \mathrm{b}, \mathrm{c}}$ Mean values with unlike superscript letters were significantly different $(P<0.05)$. 
Table 1. Average daily maternal intakes of energy and nutrients per body weight during the pre-gestational, gestational and

\begin{tabular}{|c|c|c|c|c|c|c|}
\hline \multirow[t]{2}{*}{ Period } & \multirow[t]{2}{*}{ Group } & \multicolumn{5}{|c|}{ Dietary intake } \\
\hline & & Energy $(\mathrm{kJ} / \mathrm{g} / \mathrm{d})$ & Fat $(g / g / d) \dagger$ & Protein $(g / g / d) \S$ & Carbohydrate $(\mathrm{g} / \mathrm{g} / \mathrm{d}) \ddagger$ & $\mathrm{Na}(\mathrm{mg} / \mathrm{g} / \mathrm{d}) ¥$ \\
\hline \multirow{4}{*}{$\begin{array}{l}\text { Pre-gestational } \\
\text { intakes } \\
\text { (weeks }-7 \text { to } 0 \text { ) }\end{array}$} & $\mathrm{CON}$ & $1.357 \pm 0.060$ & $0.002 \pm 0.001^{\mathrm{a}}$ & $0.019 \pm 0.001^{\mathrm{a}}$ & $0.058 \pm 0.003^{\mathrm{a}, \mathrm{b}}$ & $0.209 \pm 0.011^{\mathrm{a}}$ \\
\hline & CONT & $1.395 \pm 0.056$ & $0.002 \pm 0.001^{\mathrm{a}}$ & $0.019 \pm 0.001^{\mathrm{a}}$ & $0.059 \pm 0.002^{b}$ & $0.215 \pm 0.011^{\mathrm{a}}$ \\
\hline & CAF & $1.566 \pm 0.056$ & $0.016 \pm 0.001^{\mathrm{b}}$ & $0.010 \pm 0.001^{b}$ & $0.049 \pm 0.002^{\mathrm{a}, \mathrm{c}}$ & $0.293 \pm 0.011^{\mathrm{b}}$ \\
\hline & CAFT & $1.503 \pm 0.056$ & $0.016 \pm 0.001^{\mathrm{b}}$ & $0.010 \pm 0.001^{\mathrm{b}}$ & $0.045 \pm 0.002^{\mathrm{c}}$ & $0.285 \pm 0.011^{\mathrm{b}}$ \\
\hline \multirow{4}{*}{$\begin{array}{c}\text { Gestational } \\
\text { intakes } \\
\text { (weeks } 1 \text { to } 3 \text { ) }\end{array}$} & $\mathrm{CON}$ & $1.184 \pm 0.057$ & $0.002 \pm 0.001^{\mathrm{a}}$ & $0.016 \pm 0.000^{\mathrm{a}}$ & $0.050 \pm 0.002^{\mathrm{a}}$ & $0.182 \pm 0.013^{\mathrm{a}, \mathrm{b}}$ \\
\hline & CONT & $1.127 \pm 0.053$ & $0.002 \pm 0.001^{\mathrm{a}}$ & $0.016 \pm 0.000^{\mathrm{a}}$ & $0.048 \pm 0.002^{\mathrm{a}}$ & $0.173 \pm 0.012^{\mathrm{a}}$ \\
\hline & CAF & $1.259 \pm 0.053$ & $0.013 \pm 0.001^{\mathrm{b}}$ & $0.008 \pm 0.000^{\mathrm{b}}$ & $0.037 \pm 0.002^{b}$ & $0.220 \pm 0.012^{\mathrm{b}}$ \\
\hline & CAFT & $1.185 \pm 0.053$ & $0.013 \pm 0.001^{\mathrm{b}}$ & $0.007 \pm 0.000^{\mathrm{b}}$ & $0.037 \pm 0.002^{\mathrm{b}}$ & $0.227 \pm 0.012^{\mathrm{b}}$ \\
\hline \multirow{4}{*}{$\begin{array}{c}\text { Lactation } \\
\text { intakes } \\
\text { (weeks } 4 \text { to 6) }\end{array}$} & $\mathrm{CON}$ & $2.368 \pm 0.141$ & $0.004 \pm 0.002^{\mathrm{a}}$ & $0.033 \pm 0.002^{\mathrm{a}}$ & $0.101 \pm 0.005^{\mathrm{a}}$ & $0.364 \pm 0.039$ \\
\hline & CONT & $2.100 \pm 0.130$ & $0.003 \pm 0.001^{\mathrm{a}}$ & $0.029 \pm 0.001^{\mathrm{a}}$ & $0.089 \pm 1.004^{\mathrm{a}}$ & $0.323 \pm 0.036$ \\
\hline & CAF & $2.091 \pm 0.130$ & $0.023 \pm 0.001^{\mathrm{b}}$ & $0.014 \pm 0.001^{\mathrm{b}}$ & $0.54 \pm 0.004^{b}$ & $0.424 \pm 0.036$ \\
\hline & CAFT & $2.379 \pm 0.130$ & $0.023 \pm 0.001^{b}$ & $0.015 \pm 0.001^{b}$ & $0.68 \pm 0.004^{b}$ & $0.459 \pm 0.036$ \\
\hline
\end{tabular}

\section{2 lactation periods}



weeks also influenced fat intake during pre-gestation, gestation and lactation $(\mathrm{P}<0.05)$.

$\S$ Diet and study weeks significantly influenced protein intake during pre-gestation (Diet, $\mathrm{P}<0.001$; study weeks, $\mathrm{P}<0.001$ ), gestation (Diet, $\mathrm{P}<0.001$; study weeks, $\mathrm{P}<0.001$ ) and lactation (Diet, $\mathrm{P}<0.001$; study weeks, $\mathrm{P}<0.001$ ). A significant interaction between diet and study weeks also influenced protein intake during gestation and lactation $(\mathrm{P}<0.05)$.

\$ Diet and study weeks significantly influenced carbohydrate intake during pre-gestation (Diet, $\mathrm{P}=0.001$; study weeks, $\mathrm{P}<0.001$ ), gestation (Diet, $\mathrm{P}<0.001$; study weeks, $\mathrm{P}<0.001$ ) and lactation (Diet, $\mathrm{P}<0.001$; study weeks, $\mathrm{P}<0.001$ ). A significant interaction between diet and study weeks also influenced carbohydrate intake during gestation and lactation $(\mathrm{P}<0.01)$.

$¥$ Diet and study weeks significantly influenced sodium intake during pre-gestation (Diet, $\mathrm{P}<0.001$; study weeks, $\mathrm{P}<0.001$ ) and gestation 


\section{PeerJ}

a,b,c Mean values with unlike superscript letters were significantly different $(\mathrm{P}<0.05)$. 


\section{Table 2 (on next page)}

Maternal organ weight and fat depot mass

Mean values with their standard errors, $n=6$ (CON), $n=7$ (CONT, CAF and CAFT). CON, control chow diet; CONT, control chow diet supplemented with taurine; CAF, cafeteria diet; CAFT, cafeteria diet supplemented with taurine. * Diet significantly influenced liver weight $(P<0.001, A N O V A)$. § Diet significantly influenced right kidney weight $(P<0.001$, KruskalWallis). ¥ Diet significantly influenced left kidney weight $(\mathrm{P}<0.001$, Kruskal-Wallis). $¥$ Diet significantly influenced gonadal fat mass ( $P<0.001$, ANOVA). I Diet significantly influenced peri-renal fat mass $(P<0.001, A N O V A) .{ }^{a, b}$ Mean values with unlike superscript letters were significantly different $(P<0.05)$. 
Table 2. Maternal organ weight and fat depot mass

\begin{tabular}{|c|c|c|c|c|c|c|}
\hline \multirow[t]{2}{*}{ Group } & \multicolumn{6}{|c|}{ Organ weight or fat depot mass } \\
\hline & Liver* & Heart & Right kidney§ & Left kidney & Gonadal fat¥ & Peri-renal fat \\
\hline $\mathrm{CON}$ & $10.99 \pm 0.59^{\mathrm{a}}$ & $0.72 \pm 0.03$ & $1.13 \pm 0.05^{\mathrm{a}}$ & $1.05 \pm 0.04^{\mathrm{a}}$ & $1.67 \pm 0.52^{\mathrm{a}}$ & $0.58 \pm 0.22^{\mathrm{a}}$ \\
\hline CONT & $11.39 \pm 0.55^{\mathrm{a}}$ & $0.76 \pm 0.03$ & $1.15 \pm 0.04^{\mathrm{a}}$ & $1.11 \pm 0.04^{\mathrm{a}}$ & $1.67 \pm 0.48^{\mathrm{a}}$ & $0.58 \pm 0.20^{\mathrm{a}}$ \\
\hline CAF & $8.58 \pm 0.55^{b}$ & $0.77 \pm 0.03$ & $0.82 \pm 0.04^{\mathrm{b}}$ & $0.76 \pm 0.04^{b}$ & $5.92 \pm 0.48^{b}$ & $2.53 \pm 0.22^{b}$ \\
\hline CAFT & $8.12 \pm 0.55^{\mathrm{b}}$ & $0.74 \pm 0.03$ & $0.87 \pm 0.04^{b}$ & $0.82 \pm 0.04^{b}$ & $4.42 \pm 0.48^{b}$ & $2.10 \pm 0.24^{b}$ \\
\hline
\end{tabular}

2 Mean values with their standard errors, $n=6(\mathrm{CON}), \mathrm{n}=7$ (CONT, CAF and CAFT). CON, control chow diet; CONT, control chow diet

3 supplemented with taurine; CAF, cafeteria diet; CAFT, cafeteria diet supplemented with taurine.

4 * Diet significantly influenced liver weight $(\mathrm{P}<0.001$, ANOVA).

$5 \S$ Diet significantly influenced right kidney weight $(\mathrm{P}<0.001$, Kruskal-Wallis $)$.

6 † Diet significantly influenced left kidney weight $(\mathrm{P}<0.001$, Kruskal-Wallis).

$7 ¥$ Diet significantly influenced gonadal fat mass $(\mathrm{P}<0.001$, ANOVA).

8 II Diet significantly influenced peri-renal fat mass $(\mathrm{P}<0.001$, ANOVA).

$9 \quad$ a,b Mean values with unlike superscript letters were significantly different $(\mathrm{P}<0.05)$. 


\section{Table 3 (on next page)}

Concentrations of biochemical parameters in maternal plasma

Mean values with their standard errors, $n=6$ (CON), $n=7$ (CONT, CAF and CAFT). CON, control chow diet; CONT, control chow diet supplemented with taurine; CAF, cafeteria diet; CAFT, cafeteria diet supplemented with taurine. I Diet significantly influenced maternal plasma HbAlc levels ( $P=0.02$, Kruskal-Wallis) * Diet significantly influenced maternal plasma leptin levels ( $P=0.047, A N O V A)$. † Diet significantly influenced maternal plasma adiponectin levels ( $P<0.001$, Kruskal-Wallis). § Diet significantly influenced maternal plasma malondialdehyde

levels ( $P=0.02$, ANOVA). ${ }^{a, b}$ Mean values with unlike superscript letters were significantly different $(P<0.05$, ANOVA $)$. 
Table 3. Concentrations of biochemical parameters in maternal plasma

\begin{tabular}{lcccc}
\hline Biochemical Parameter & \multicolumn{4}{c}{ Study Groups } \\
\hline & CON & CONT & CAF & CAFT \\
\hline Glucose $(\mathrm{mg} / \mathrm{dL})$ & $130.56 \pm 11.23$ & $159.41 \pm 10.40$ & $123.78 \pm 11.23$ & $121.74 \pm 10.40$ \\
Insulin $(\mu \mathrm{U} / \mathrm{mL})$ & $41.34 \pm 4.77$ & $30.51 \pm 4.41$ & $26.06 \pm 4.77$ & $27.79 \pm 4.41$ \\
IGF-1 $(\mathrm{ng} / \mathrm{mL})$ & $745.21 \pm 170.80$ & $963.88 \pm 158.13$ & $1358.57 \pm 170.80$ & $773.23 \pm 158.13$ \\
C-peptide $(\mathrm{ng} / \mathrm{mL})$ & $2.22 \pm 0.23$ & $5.36 \pm 1.21$ & $4.67 \pm 1.23$ & $7.07 \pm 1.21$ \\
HbAlc $\uparrow(\mathrm{ng} / \mathrm{mL})$ & $12.06 \pm 1.80^{\mathrm{a}}$ & $20.84 \pm 1.81^{\mathrm{b}}$ & $27.19 \pm 1.80^{\mathrm{b}}$ & $20.30 \pm 1.85^{\mathrm{b}}$ \\
Cholesterol $(\mathrm{mmol} / \mathrm{L})$ & $2.89 \pm 0.15$ & $2.57 \pm 0.14$ & $2.76 \pm 0.15$ & $2.59 \pm 0.14$ \\
Triglycerides $(\mathrm{mmol} / \mathrm{L})$ & $1.49 \pm 0.18$ & $1.56 \pm 0.19$ & $1.55 \pm 0.19$ & $1.31 \pm 1.18$ \\
Leptin $(\mathrm{ng} / \mathrm{mL})^{*}$ & $0.55 \pm 0.09^{\mathrm{a}}$ & $0.63 \pm 0.09^{\mathrm{a}}$ & $0.93 \pm 0.09^{\mathrm{b}}$ & $0.76 \pm 0.09^{\mathrm{a}, \mathrm{b}}$ \\
Adiponectin $(\mu \mathrm{g} / \mathrm{mL}) \dagger$ & $3.09 \pm 1.58^{\mathrm{a}}$ & $3.52 \pm 1.46^{\mathrm{a}}$ & $11.53 \pm 1.58^{\mathrm{b}}$ & $15.73 \pm 1.58^{\mathrm{b}}$ \\
Malondialdehyde $(\mu \mathrm{M}) \S$ & $11.76 \pm 4.48^{\mathrm{a}}$ & $21.74 \pm 4.15^{\mathrm{a}}$ & $32.69 \pm 4.48^{\mathrm{b}}$ & $16.86 \pm 4.15^{\mathrm{a}}$ \\
\hline
\end{tabular}

2 
11 Mean values with their standard errors, $n=6(\mathrm{CON}), \mathrm{n}=7$ (CONT, CAF and CAFT). CON, control chow diet; CONT, control chow diet 12 supplemented with taurine; CAF, cafeteria diet; CAFT, cafeteria diet supplemented with taurine.

13 I Diet significantly influenced maternal plasma HbA1c levels $(\mathrm{P}=0.02$, Kruskal-Wallis $)$

$14 *$ Diet significantly influenced maternal plasma leptin levels ( $\mathrm{P}=0.047$, ANOVA).

$15 \dagger$ Diet significantly influenced maternal plasma adiponectin levels $(\mathrm{P}<0.001$, Kruskal-Wallis).

$16 \S$ Diet significantly influenced maternal plasma malondialdehyde levels $(\mathrm{P}=0.02, \mathrm{ANOVA})$.

17 a,b Mean values with unlike superscript letters were significantly different $(\mathrm{P}<0.05, \mathrm{ANOVA})$. 


\section{Table 4 (on next page)}

Concentrations of amino acids in maternal plasma

Mean values with their standard errors, $n=6$ (CON), $n=7$ (CONT, CAF and CAFT). CON, control chow diet; CONT, control chow diet supplemented with taurine; CAF, cafeteria diet; CAFT, cafeteria diet supplemented with taurine. * Diet significantly influenced plasma aspartic acid concentrations $(P<0.001, A N O V A) \dagger$ Diet significantly influenced plasma phenylalanine concentrations ( $P=0.045, A N O V A) \S$ Diet significantly influenced plasma serine concentrations $(P<0.001, A N O V A) \ddagger$ Diet significantly influenced plasma tyrosine concentrations ( $P=0.008$, Kruskal-Wallis) I Diet significantly influenced plasma taurine concentrations ( $P<0.001$, Kruskal-Wallis) ${ }^{a, b, c}$ Mean values with unlike superscript letters were significantly different $(P<0.05)$ 
Table 4. Concentrations of amino acids in maternal plasma (mean values with their standard errors, $\mathbf{n}=6-7$ )

\begin{tabular}{|c|c|c|c|c|}
\hline \multicolumn{5}{|c|}{ Amino acids $(\mu \mathrm{mol} / \mathrm{L})$} \\
\hline & $\mathrm{CON}$ & CONT & CAF & CAFT \\
\hline Alanine & $1395.82 \pm 123.51$ & $1286.27 \pm 114.35$ & $1389.92 \pm 123.51$ & $1196.91 \pm 114.35$ \\
\hline Asparagine & $104.54 \pm 8.01$ & $81.49 \pm 7.42$ & $85.43 \pm 8.01$ & $82.59 \pm 7.42$ \\
\hline Aspartic acid* & $884.70 \pm 93.41^{\mathrm{a}}$ & $931.75 \pm 86.48^{\mathrm{a}}$ & $1226.15 \pm 93.41^{\mathrm{a}, \mathrm{b}}$ & $1473.46 \pm 86.48^{b}$ \\
\hline Phenylalanine $\dagger$ & $1047.72 \pm 70.25^{\mathrm{a}}$ & $943.44 \pm 65.04^{\mathrm{a}, \mathrm{b}}$ & $831.10 \pm 70.25^{\mathrm{a}, \mathrm{b}}$ & $775.27 \pm 65.04^{\mathrm{b}}$ \\
\hline Glycine & $721.94 \pm 58.33$ & $774.16 \pm 53.99$ & $723.66 \pm 58.33$ & $589.13 \pm 53.99$ \\
\hline Glutamic acid & $370.66 \pm 65.59$ & $362.06 \pm 60.73$ & $436.48 \pm 65.59$ & $483.81 \pm 60.73$ \\
\hline Glutamine & $328.56 \pm 84.10$ & $276.20 \pm 77.86$ & $383.76 \pm 84.10$ & $306.11 \pm 77.86$ \\
\hline Histidine & $148.90 \pm 15.34$ & $149.09 \pm 14.21$ & $138.04 \pm 15.34$ & $165.70 \pm 14.21$ \\
\hline Isoleucine & $177.64 \pm 14.63$ & $152.56 \pm 13.54$ & $147.57 \pm 14.63$ & $146.25 \pm 13.54$ \\
\hline Lysine & $1845.06 \pm 166.31$ & $1911.47 \pm 153.97$ & $1826.96 \pm 166.31$ & $2216.45 \pm 153.97$ \\
\hline Leucine & $358.83 \pm 27.33$ & $308.95 \pm 25.30$ & $269.25 \pm 27.33$ & $272.11 \pm 25.30$ \\
\hline Methionine & $201.70 \pm 28.16$ & $205.31 \pm 26.07$ & $164.34 \pm 28.16$ & $169.19 \pm 26.07$ \\
\hline Ornithine & $306.06 \pm 49.88$ & $313.74 \pm 46.18$ & $261.22 \pm 49.88$ & $181.25 \pm 46.18$ \\
\hline Proline & $283.99 \pm 22.29$ & $264.72 \pm 20.64$ & $319.95 \pm 22.29$ & $299.37 \pm 20.64$ \\
\hline Serine $\S$ & $623.55 \pm 124.60^{\mathrm{a}}$ & $548.92 \pm 115.36^{\mathrm{a}}$ & $1288.82 \pm 124.60^{\mathrm{b}}$ & $1277.52 \pm 115.36^{b}$ \\
\hline Cystine & $24.24 \pm 4.34$ & $26.32 \pm 5.02$ & $16.80 \pm 3.89$ & $16.63 \pm 3.55$ \\
\hline
\end{tabular}

2 


$$
\text { Amino acid s }(\mu \mathrm{mol} / \mathrm{L})
$$

5

6

7

Table 4. Concentrations of amino acids in maternal plasma (mean values with their standard errors, $n=6-7)($ cont.) 


\begin{tabular}{lcccc}
\hline & CON & CONT & CAF & CAFT \\
\hline Tyrosine $t$ & $147.64 \pm 9.42^{\mathrm{a}}$ & $127.09 \pm 8.72^{\mathrm{a}}$ & $103.73 \pm \pm 9.42^{\mathrm{b}}$ & $98.54 \pm 8.72^{\mathrm{b}}$ \\
Threonine & $496.53 \pm 44.89$ & $405.01 \pm 41.56$ & $414.88 \pm 44.89$ & $435.25 \pm 41.56$ \\
Tryptophan & $139.10 \pm 16.31$ & $169.02 \pm 15.10$ & $107.18 \pm 16.31$ & $121.74 \pm 15.10$ \\
Valine & $354.81 \pm 29.85$ & $327.37 \pm 27.64$ & $275.34 \pm 29.85$ & $299.11 \pm 27.64$ \\
Cystathionine & $22.96 \pm 2.96$ & $26.11 \pm 2.96$ & $18.69 \pm 2.96$ & $21.07 \pm 2.74$ \\
Alpha-aminoadipic acid & $967.51 \pm 374.54$ & $327.64 \pm 346.75$ & $2338.30 \pm 374.54$ & $555.52 \pm 346.75$ \\
Taurineq & $287.16 \pm 44.49^{\mathrm{a}}$ & $473.24 \pm 41.19^{\mathrm{c}}$ & $151.83 \pm 44.49^{\mathrm{b}}$ & $291.16 \pm 41.19^{\mathrm{a}}$ \\
\hline
\end{tabular}

Mean values with their standard errors, $n=6(\mathrm{CON}), \mathrm{n}=7$ (CONT, CAF and CAFT). CON, control chow diet; CONT, control chow diet supplemented with taurine; CAF, cafeteria diet; CAFT, cafeteria diet supplemented with taurine.

* Diet significantly influenced plasma aspartic acid concentrations $(\mathrm{P}<0.001$, ANOVA)

$\dagger$ Diet significantly influenced plasma phenylalanine concentrations ( $\mathrm{P}=0.045$, ANOVA)

$\S$ Diet significantly influenced plasma serine concentrations $(\mathrm{P}<0.001$, ANOVA) 
31 † Diet significantly influenced plasma tyrosine concentrations ( $\mathrm{P}=0.008$, Kruskal-Wallis)

32 II Diet significantly influenced plasma taurine concentrations $(\mathrm{P}<0.001$, Kruskal-Wallis $)$

33 a,b,c Mean values with unlike superscript letters were significantly different $(\mathrm{P}<0.05)$ 


\section{Table 5 (on next page)}

Organ weight of offspring at the end of lactation (\% body weight)

Mean values with their standard errors, $n=12$ (CON, males), $n=22$ (CON, female), $n=14$ (CONT, male), $n=17$ (CONT, female), $n=18$ (CAF, male), $n=15$ (CAF, female), $n=20$ (CAFT, male) and $n=19$ (CAFT, female). CON, control chow diet; CONT, control chow diet supplemented with taurine; CAF, cafeteria diet; CAFT, cafeteria diet supplemented with taurine. * Maternal diet significantly influenced liver weight $(P<0.001)$. † Maternal diet significantly influenced brain weight $(P=0.001)$. ₹ Maternal diet significantly influenced right kidney weight $(P<0.001)$. $¥$ Maternal diet and sex of the animals significantly influenced left kidney weight (Maternal Diet, $\mathrm{P}<0.001 ;$ Sex, $\mathrm{P}<0.05$ ). § Maternal diet significantly influenced heart weight $(P<0.001)$. 
Table 5. Organ weight of offspring at the end of lactation (\% body weight)

Liver* $\quad$ Brain $\dagger \quad$ Right kidney

\begin{tabular}{|c|c|c|c|c|c|c|}
\hline Sex & Group & & & & & \\
\hline \multirow[t]{4}{*}{ Male } & $\mathrm{CON}$ & $4,31 \pm 0,11^{\mathrm{a}}$ & $3,58 \pm 0,13^{\mathrm{a}}$ & $0,66 \pm 0,02^{\mathrm{a}}$ & $0,62 \pm 0,02^{\mathrm{a}}$ & $0,51 \pm 0,02^{\mathrm{a}}$ \\
\hline & CONT & $3,91 \pm 0,11^{\mathrm{b}}$ & $3,57 \pm 0,12^{\mathrm{a}}$ & $0,59 \pm 0,02^{\mathrm{a}}$ & $0,55 \pm 0,02^{\mathrm{a}}$ & $0,51 \pm 0,02^{\mathrm{a}}$ \\
\hline & CAF & $3,43 \pm 0,10^{\mathrm{c}}$ & $3,87 \pm 0,11^{\mathrm{a}, \mathrm{b}}$ & $0,55 \pm 0,02^{\mathrm{b}}$ & $0,51 \pm 0,02^{b}$ & $0,57 \pm 0,01^{b}$ \\
\hline & CAFT & $3,45 \pm 0,10^{\mathrm{c}}$ & $4,08 \pm 0,10^{\mathrm{b}}$ & $0,56 \pm 0,02^{\mathrm{b}}$ & $0,52 \pm 0,02^{\mathrm{b}}$ & $0,51 \pm 0,01^{\mathrm{a}}$ \\
\hline \multirow[t]{4}{*}{ Female } & $\mathrm{CON}$ & $4,25 \pm 0,09^{\mathrm{a}}$ & $3,59 \pm 0,10^{\mathrm{a}}$ & $0,65 \pm 0,01^{\mathrm{a}}$ & $0,61 \pm 0,02^{\mathrm{a}}$ & $0,51 \pm 0,01^{\mathrm{a}}$ \\
\hline & CONT & $3,95 \pm 0,09^{b}$ & $3,51 \pm 0,11^{\mathrm{a}}$ & $0,63 \pm 0,02^{\mathrm{a}}$ & $0,61 \pm 0,02^{\mathrm{a}}$ & $0,53 \pm 0,02^{\mathrm{a}}$ \\
\hline & CAF & $3,47 \pm 0,10^{\mathrm{c}}$ & $3,64 \pm 0,12^{\mathrm{a}, \mathrm{b}}$ & $0,56 \pm 0,02^{b}$ & $0,54 \pm 0,02^{\mathrm{b}}$ & $0,55 \pm 0,02^{\mathrm{b}}$ \\
\hline & CAFT & $3,49 \pm 0,09^{\mathrm{c}}$ & $3,85 \pm 0,10^{b}$ & $0,58 \pm 0,02^{\mathrm{b}}$ & $0,56 \pm 0,02^{b}$ & $0,53 \pm 0,02^{\mathrm{a}}$ \\
\hline
\end{tabular}

2 Mean values with their standard errors, $n=12$ (CON, males), $n=22$ (CON, female), $n=14$ (CONT, male), $n=17$ (CONT, female), $n=18$

3 (CAF, male), $n=15$ (CAF, female), $n=20$ (CAFT, male) and $n=19$ (CAFT, female). CON, control chow diet; CONT, control chow diet 4 supplemented with taurine; CAF, cafeteria diet; CAFT, cafeteria diet supplemented with taurine.

$5 *$ Maternal diet significantly influenced liver weight $(\mathrm{P}<0.001$, ANOVA).

$6 \uparrow$ Maternal diet significantly influenced brain weight $(\mathrm{P}=0.001$, ANOVA).

$7 \ddagger$ Maternal diet significantly influenced right kidney weight $(\mathrm{P}<0.001$, ANOVA).

$8 ¥$ Maternal diet and sex of the animals significantly influenced left kidney weight (Maternal Diet, P<0.001; Sex, P $<0.05$, ANOVA).

$9 \S$ Maternal diet significantly influenced heart weight $(\mathrm{P}<0.001$, ANOVA). 